1990

\title{
Reaction Time Crossover in Schizotypal Subjects
}

Holly B. Drewer

College of William \& Mary - Arts \& Sciences

Follow this and additional works at: https://scholarworks.wm.edu/etd

Part of the Clinical Psychology Commons

\section{Recommended Citation}

Drewer, Holly B., "Reaction Time Crossover in Schizotypal Subjects" (1990). Dissertations, Theses, and Masters Projects. Paper 1539625639.

https://dx.doi.org/doi:10.21220/s2-5xpr-ws60

This Thesis is brought to you for free and open access by the Theses, Dissertations, \& Master Projects at W\&M ScholarWorks. It has been accepted for inclusion in Dissertations, Theses, and Masters Projects by an authorized administrator of W\&M ScholarWorks. For more information, please contact scholarworks@wm.edu. 
REACTION TIME CROSSOVER IN SCHIZOTYPAL SUBJECTS

\begin{abstract}
A Thesis
Presented to

The Faculty of the Department of Psychology

The College of William and Mary in Virginia
\end{abstract}

\author{
In Partial Fulfillment \\ of the Requirements for the Degree of \\ Master of Arts
}

by

Holly B. Drewer

1990 
APPROVAL SHEET

This thesis is submitted in partial fulfillment of the requirements for the degree of

Master of Arts

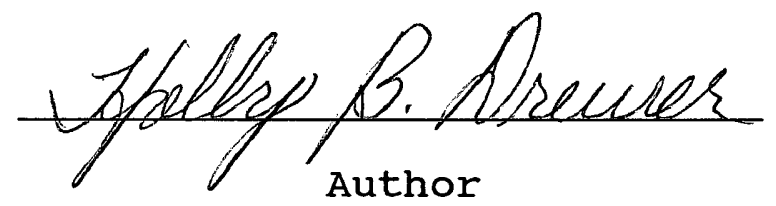

Approved, May 1990

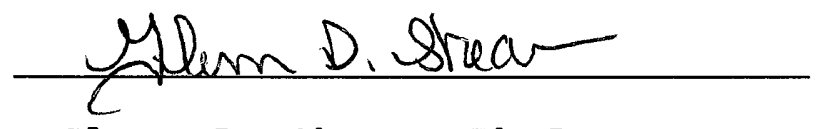

Glenn D. Shear, Ph.D.

Gotta IV Bull

Cynthia H. Null, Ph.D.

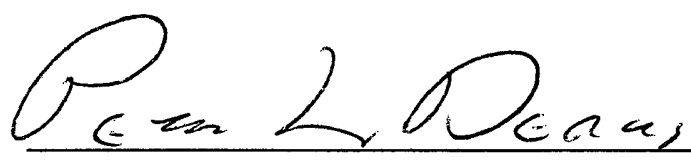

Peter L. Berks, Ph.D.

ii 
ACKNOWLEDGEMENTS .............. . . . iv

LIST OF TABLES .................... v v

LIST OF FIGURES . . . . . . . . . . . . . . . . . . vi

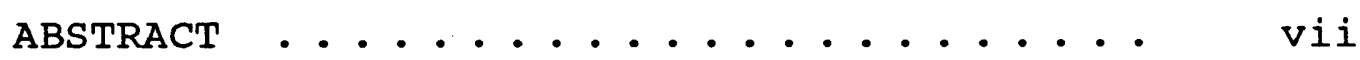

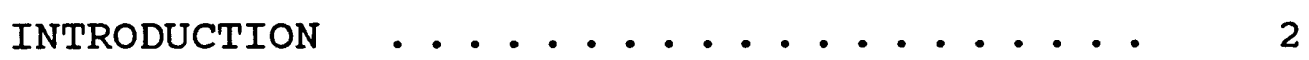

EXPERIMENT 1 .......................... 14

EXPERIMENT 2 . . . . . . . . . . . . . . . . . . . 24

GENERAL DISCUSSION .............. 31

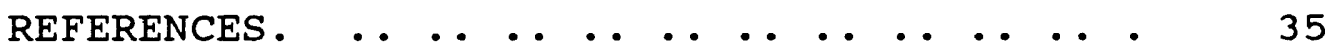

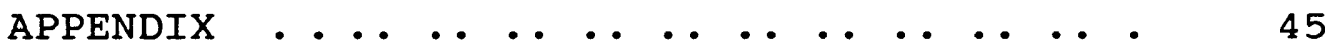

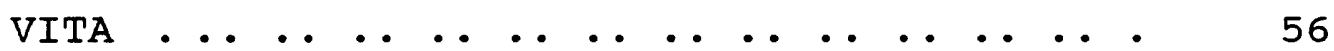




\section{ACKNOWLEDGEMENTS}

The author is grateful to Professors Glenn Shean and Cynthia Null under whose guidance this study was conducted. She also wishes to thank Professor Cynthia Null for her technical expertise in programming the information-processing task and her many hours of statistical consultation. She also wishes to thank Professor Kelly Shaver for his computer expertise. This thesis is dedicated to Newman and Bonnie Drewer, whose love and encouragement make anything possible. 


\section{LIST OF TABLES}

Table

1. Mean Reaction Time Scores as a Function of Type, Distraction, and Pattern for

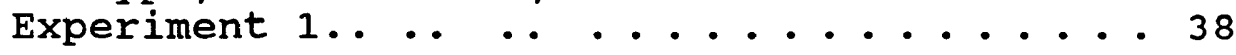

2. Mean Reaction Time Scores as a Function

of Type, Distraction, and Pattern

for Experiment 2............... . . 39

3. Point Biserial Correlations between Scores and the RISC for Experiments 1 and 2....................... 40 


\section{LIST OF FIGURES}

Figure

Page

1. Reaction time performance as a function of Pattern and Preparatory Interval (PI) for schizotypal and nonschizotypal subjects in the nondistraction condition. . . . . 42

2. Reaction time performance as a function of Pattern and Preparatory Interval (PI) for schizotypal and nonschizotypal subjects in the distraction condition. . . . . . . . . 44 


\begin{abstract}
The present study was designed to investigate the construct validity of schizotypy as measured by the Physical Anhedonia Scale (PAS; Chapman, Chapman, \& Raulin, 1976).

This study consisted of two experiments. In Experiment 1, 20 PAS-identified schizotypal college students were administered a computerized version of Rodnick and Shakow's (1940) reaction time (RT) task with an auditory distraction condition. In Experiment 2, 16 PAS-identified schizotypal subjects and 17 PAS-identified nonschizotypal subjects were administered the same RT task with a more meaningful distractor. Reaction time data were analyzed with a 2 (Group) $x 2$ (PI Pattern) $x 2$ (Distraction) $\times 6$ (PI) analysis of variance.

In Experiment 1, the hypothesized interaction between PI duration and PI presentation was observed for the PAS-identified schizotypics in the nondistraction condition. The hypothesized crossover effect was not observed in the distraction condition. In Experiment 2, the hypothesized crossover effect for the schizotypal subjects was not observed for either the nondistraction or the distraction conditions.

Results are discussed in terms of Zubin and Spring's (1977) vulnerability theory.
\end{abstract}


REACTION TIME CROSSOVER IN SCHIZOTYPAL SUBJECTS 
Introduction

Since Meehl's proposal of an invariant personality organization (Meehl, 1962), schizotypy, the hypothesized personality trait constellation associated with a schizophrenic diathesis, Zubin and spring (1977) have developed a trait-state vulnerability model to define individuals at risk for schizophrenia. schizotypy, as defined by Meehl, is based on the assumption of a genetic predisposition (schizotaxia) hypothesized to be necessary, but not sufficient, for a schizophrenic episode to occur. Based on Meehl's diathesis-stress reasoning, Zubin and Spring's (1977) vulnerability model states that exogenous and/or endogenous challengers may elicit a crisis in all humans. Depending on the intensity of the elicited stress and the presence of a genetic predisposition, the authors propose that a crisis will either be contained or lead to an episode of schizophrenic disorder. Vulnerability and episode therefore stand in a trait-state relation. It is within this theoretical framework that scientists have begun to research trait markers proposed to identify individuals prone to a schizophrenic episode.

Earlier research, based on the diathesis-stress model, focused upon diagnosed schizophrenics and their offspring. offspring of schizophrenics who are raised by their parents have been reported to be approximately ten times more likely to develop schizophrenic symptomatology than persons 
randomly selected from the population (Rosenthal, 1970). Given conservative estimates of the prevalence of the disorder ranging from $.2 \%$ to $1.0 \%$ (American Psychiatric Association, 1987, cited in Lowrie \& Raulin, 1990), one would therefore expect that only $10 \%$ or so of these highrisk cases will eventually develop schizophrenic symptoms. This relatively low incidence rate among first degree relatives presents a considerable impediment to adequate sampling for high-risk research. In order to obtain a schizophrenic sample of a sufficient size to allow statistically meaningful inferences to be made, a large initial sample of several high-risk subjects would be necessary. These sampling problems are among those that have led investigators to develop alternative strategies. Researchers therefore have attempted to construct selfreport inventories which purport to identify characteristics of schizotypic individuals hypothetically prone to schizophrenia. These measures are based largely on attempts to measure observed constructs/traits derived from clinical literature on "pre-schizophrenic" traits. Available selfreport measures include the Physical Anhedonia Scale (PAS; Chapman, Chapman, \& Raulin, 1976); the Social Anhedonia Scale (Chapman, Chapman, \& Raulin, 1976); the Perceptual Aberration Scale (Chapman, Chapman, \& Raulin, 1978); the Magical Ideation Scale (Eckblad \& Chapman, 1983); and the Rust Inventory of Schizotypal Cognitions (RISC; Rust, 
1989). Each scale was developed to have high internal consistency and minimal method variance. Test-retest reliabilities indicate that measures of these traits are stable within normal populations, regardless of fluctuations in expressed symptomatology (Lowrie \& Raulin, 1990).

Subjects with elevations on these schizotypy scales have been shown to display, to a greater degree than normals, impairment in functioning characteristic of schizophrenic patients (Lowrie \& Raulin, 1990). Specifically, subjects with elevated scores on the Physical Anhedonia Scale produce deviant Rorschach protocols (Edell \& Chapman, 1979) and appear less socially competent during behavioral tests than do controls (Haberman, Chapman, Numbers, \& McFall, 1979). Also, like schizophrenic patients, these subjects have been shown to be electrodermally underresponsive in psychophysiological experiments (Simons, 1981) and to produce smaller P300 components in scalp-recorded event-related potentials (Simons, 1982).

Drewer and Shean (1989) investigated the relationship between the scales of Physical Anhedonia, Social Anhedonia, Perceptual Aberration, Magical Ideation, and Eysenck's Personality Questionnaire (1976) and reaction time (as measured by sternberg's information-processing task). Among these measures, only the Physical Anhedonia scale PAs was significantly correlated with delayed reaction time. 
Chapman et al. (1976) developed the PAS as a measure of Meehl's construct of anhedonia. Meehl (1962) stated that there is a quasi-pathognomonic sign, anhedonia, which is a marked, widespread, and refractory defect in pleasure capacity that is one of the most consistent and dramatic behavioral signs of schizophrenia. This defect prevents development of normal healthy sexual functioning, decreased zest for life, and impairs ability to relate to others.

The trait-marker of schizophrenia proposed by Meehl's (1962) diathesis-stress model is considered to be "cognitive slippage." Meehl argues that the thought disorder of individuals diagnosed with schizophrenia is in part a function of disordered attentional processing deficits. It is within this framework that researchers have utilized the reaction time (RT) paradigm as a tool to analyze schizophrenic attentional dysfunction as a trait-marker of vulnerability.

Rodnick and Shakow (1940) first employed reaction time to preparatory intervals (PI) (the temporal interval between a warning and a stimulus) of various lengths as a quantitative measure of the ability of the schizophrenic to reach and maintain a high level of preparation in meeting recurrent environmental stimuli. The technique consisted of two procedures: the "regular" procedure in which the various PIs remained the same for a series of trials before an interval of another length was presented; 
and the "irregular" procedure in which the various PIs were presented in a random order. The irregular procedure prevents any prior knowledge of the length of the PI. The regular warning procedure favors a faster reaction time, since the subject is then able to reach a higher state of preparation than would be possible with the irregular warning procedure. The difference in the reaction times of the two procedures serves as a measure of the ability of the subject to adopt an optimal set under the conditions of the regular procedure.

The results of this study clearly differentiated between the schizophrenic group and the control group: The response latencies of the schizophrenics were significantly slower than the controls. The scores of the schizophrenic group also resulted in a "crossover" of the regular and irregular performance gradients when plotted across PI duration. That is, reaction time performance under regular PIs was not just reduced to the same level but was impaired relative to the performance of the irregular PIs (Bellissimo \& Steffy, 1972), indicating that schizophrenics are unable to benefit from stimulus predictability.

Shakow (1963) postulated that efficient performance on a RT task requires the maintenance of a major response set (state of readiness). Somehow, prior to the onset of the critical stimulus, schizophrenics are distracted and their major set is disrupted. Specifically, the crossover is 
believed to result from the schizophrenic's undue attention to the length of the preceding PI (Zahn, Rosenthal, \& Shakow, 1963).

In order to test the resiliency of the crossover phenomenon, Bellissimo and Steffy (1975) manipulated the contextual influences operating within the arrangement of trials. Neither eliminating the presence of shorter trials preceding the irregular test trials (a condition expected to dampen the effect) nor loading the series with shorter duration trials (a condition expected to increase the magnitude of the effect) substantially influenced the extent to which the long regular trials were slower than the long irregular trials (Bellissimo \& Steffy, 1975). This crossover effect was found to be most characteristic of the process schizophrenic group as opposed to reactive schizophrenic, or normal control groups.

Oltmanns (1978) suggested that the effects of distraction might shed some light on the relationship between attention and schizophrenia. Oltmanns, Ohayon, and Neale (1978) found that among schizophrenics the symptom that correlated most highly with an objective index of distractibility was thought disorder. Oltmanns et al. (1978) demonstrated a differential deficit between neutral and distractor items using sets of neutral and distractor word-span tests. During the presentation of distractor lists, schizophrenics did not efficiently select relevant 
items for active rehearsal. For many schizophrenics, the presence of salient extraneous stimuli appeared to disrupt the controlled processes of rote rehearsal, coding, and some forms of memory search (Oltmanns, 1978).

Lawson, McGhie, and Chapman (1967) found that while auditory span of apprehension was decreased by auditory distraction, visual span of apprehension was unaffected by the presence of visual distractors. Oltmanns and Neale (1975) and oltmanns (1978) also demonstrated the presence of a specific susceptibility to auditory distraction on the part of schizophrenic subjects. Knight, Youard, and Wooles (1985) postulated that the apparent greater vulnerability of schizophrenic patients to distraction when processing auditory, as opposed to visual information results from the different extent to which distractors disrupt active central processing. The apparent greater vulnerability of schizophrenic patients to distraction when processing auditory, as opposed to visual information may result from differences in the extent to which distractors disrupt active central processing.

Ohman and Nordby (1986) tested the hypothesis that poor performance among schizophrenics is associated with less orienting to task-relevant stimuli and more orienting to task-irrelevant stimuli. They employed a signaled RT task in which one tone was followed by an imperative noise stimulus. During one phase of the experiment, distracting 
stimuli were presented both between and during RT trials. The schizophrenics exhibited significantly slower RTs, less overall responding than the control group, and very limited differential responses to signal and nonsignal stimuli. The schizophrenic patients appeared to orient less efficiently than controls to experimental stimuli. Thus, they tended to respond less than controls to task-important events and more than controls to task-irrelevant events.

Research has strongly supported a crossover phenomenon in the schizophrenic patient within a RT paradigm. The robustness of the paradigm and the reliability of the crossover pattern across studies has prompted researchers to investigate the possibilities of RT crossover as an indexmarker of vulnerability (Spring, Nuechterlein, Sugarman, \& Matthysse, 1977; Steffy \& Galbraith, 1980; Simons, MacMillan, \& Ireland, 1982). To qualify as an index, a vulnerability indicator must be specific to the disorder, and it must not be secondary to other effects associated with the disorder. Furthermore, the indicator must be observable in individuals not currently symptomatic but known to be vulnerable (Simons et al., 1982).

DeAmicis and Cromwell (1979) investigated RT crossover in process schizophrenic patients, their relatives, and control subjects. The nondisturbed relatives exhibited RT crossover significantly greater than controls. A crossover pattern was found by Strauss, Bohannon, Kaminsky, and 
Kharabi (1979) in schizophrenic outpatients.

Steffy and Galbraith (1980) evaluated the RT measures of latency and crossover in process schizophrenic patients to distinguish between state-linked and trait-linked markers. Training exercises were designed to improve the speed of RT performance. These exercises were successful in reducing latency over the course of training and from preto post- training assessments, with scores falling around the range of the expected performance of normal subjects. The crossover pattern did not change from the pre-assessment to the post-assessment, which indicates that this index is not a simple reflection of latency and is not responsive to training procedures involving positive motivation. Intercorrelations of the two indices showed that these measures were independent. The latency measure correlated with measures of chronicity; and the crossover pattern correlated with prognosis.

Thus far, the RT paradigm has provided consistent findings with process schizophrenics, schizophrenic outpatients, and first degree relatives of schizophrenics. Such findings suggest that the phenomena associated with a predisposition to schizophrenia lies on a continuum. If so, then the position of an individual on this continuum should be psychometrically measurable using Chapman's PAS and Shakow's RT paradigm (1940). Simons et al. (1982) defined a hypothetically 
schizotypic sample from undergraduate psychology students using Chapman's Perceptual Aberration Scale and the PAS (Chapman et al., 1976). Both groups of schizotypic subjects showed evidence of RT crossover relative to control subjects. These results are similar to those reported by steffy and Galbraith (1980) with schizophrenic patients performing under high-incentive conditions. In both studies, mean RTs across groups were comparable, yet the RT pattern over PI variables was group-specific.

Rosenbaum, Shore, and Chapin (1988) utilized the Minnesota Multiphasic Personality Inventory (MMPI) to classify schizotypic subjects, elevation controls, and normal subjects to compare with a target group of male schizophrenics on a replication of the Rodnick and shakow (1940) procedure. The results demonstrated that the schizophrenic patients and the schizotypic normals displayed earlier RT crossover than did the control student groups, whereas only the hospitalized schizophrenic group showed longer mean RTs. Rosenbaum et al. (1988) suggest that RTprocedure- generated measures may prove to be powerful in isolating brain mechanisms underlying attentional dysfunction.

This study was designed to investigate the construct validity of schizotypy as measured by the PAS. Subjects were selected according to their scores on the PAS. Auditory distraction was applied to Rodnick and Shakow's 
(1940) RT procedure as a measure of the ability to maintain attention. As observed in other studies, an interaction between PI duration and PI regularity in the form of a crossover is expected for only the PAS-identified schizotypics. If, as suggested in previous studies, PASidentified schizotypics exhibit a crossover phenomenon due to more orienting to task-irrelevant stimuli (distractor condition) as opposed to orienting to task-relevant stimuli, the auditory distraction should have the effect of magnifying the crossover for the PAS-identified subjects, as evidenced by an interaction between PI pattern (regular vs. irregular), PI duration, and distraction. It was also hypothesized that slower mean latencies would be observed for the PAS-identified schizotypics in the distraction condition.

The RISC, which assesses the schizotypal cognitions associated with the positive symptoms of acute schizophrenia and schizotypal personality disorder, will be administered to all subjects. Since this scale measures cognitions associated with positive symptoms, and the PAS measures cognitions more similar to the negative symptoms of schizophrenia, it is expected that these scales will be negatively correlated. It is also expected that RTs will be negatively correlated with the RISC. 
Experiment 1

Method

Subjects

Students enrolled in introductory psychology classes at a small southeastern university served as subjects. Approximately 600 students, ages 18 and older, were administered an abbreviated version (25 questions) of Chapman's Physical Anhedonia Scale (1976) as part of a battery of tests given early in the fall semester. Participation was voluntary. Four hundred and sixteen protocols were returned.

Students were selected according to the criterion utilized by Chapman et al. (1976), i.e., those scoring 2 deviations above the mean were selected for the hypothetically schizotypal group, and those scoring 2 standard deviations below the mean were selected for the nonschizotypal group. The mean of the PAS scores from the fall mass testing was 4.22 , with a standard deviation of 3. 01 .

Students were contacted by phone by the experimenter and asked to participate in a study about personality and attention. Of the 58 students who were contacted, 43 agreed to participate. Due to a computer malfunction, 3 subjects' data were discarded after they participated in the RT task component. Both the hypothetically schizotypal and the nonschizotypal group consisted of 20 subjects. Students 
participating in the study received one hour of credit toward completion of a course research requirement.

\section{Apparatus}

An IBM personal computer was used to provide a measure of simple reaction time. Rodnick and Shakow's (1940) paradigm, which tests simple RT to a visual stimulus presented following the Preparatory Intervals (PI) of 1, 2, 4, 7.5, 15, and $25 \mathrm{~s}$, was employed. These PIs were presented in two sets of a fixed and random series of trials. During the first regular series, 10 trials at one PI was presented consecutively and then followed by 10 trials at another PI, in the order of $1,25,2,15,4$, and $7.5 \mathrm{~s}$. Trials were separated by 5-s intervals with a 60-s rest period following each 10-trial series at a given PI. During the irregular series, 12 trials of each PI were presented in a sequence in which each PI preceded every other PI at least once; and two of the same PIs were never presented in succession. This procedure was repeated employing an auditory distractor which sounded between the visual preparation signal and the visual stimulus. A 5-s intertrial interval was also provided in the irregular procedure, and a 3-min rest period followed the administration of 36,72 , and 108 irregular procedure trials.

Reaction time was measured by the computer to the millisecond. Subjects' identification number and RTs of the 
regular and irregular trials were recorded on a data disk.

The auditory distractor was programmed using a casio HX900 synthesizer with instrument timbre set at "typhoon." The distractor was delivered binaurally to the subjects through headphones connected to the synthesizer.

\section{Personality Measures}

Physical Anhedonia Scale (Chapman et al., 1976). originally a 62 - item true/false questionnaire, the current study utilized only the 25 items that were most highly correlated with an overall rating of anhedonia (Appendix A). The PAS is designed to assess physical anhedonia, as defined by a marked decrease in pleasure capacity.

Rust Inventory of Schizotypal Cognitions (Rust, 1989). A 26 - item questionnaire, each symptom-related item is followed by four response options which indicate an individual's level of endorsement of each statement. The RISC is designed to assess the schizotypal cognitions associated with the positive symptoms of acute schizophrenia. It differs from previous scales in having been developed and standardized with special attention to normal distribution in the general population, and in emphasizing cognitive content rather than cognitive deficit. Manipulation check

During the debriefing session, the first 6 subjects reported that the distractor was not "distracting" and was similar to "background music used while studying." 
Therefore the following 15 subjects were asked to rate, on a scale from 1 (least distracting) to 10 (most distracting), how distracting they found the distractor (Appendix B). $\underline{\text { Procedure }}$

Once subjects were chosen (as outlined above), each was contacted by telephone. All subjects were informed that they would be asked to complete two questionnaires and participate in a RT task requiring them to press the designated key when a visual stimulus appeared on the computer screen. Both written and verbal informed consents (Appendix D) were obtained from all subjects who participated in the study.

The information-processing task, the PAS, and the RISC were administered to subjects individually. Order of presentation was the same for all subjects. Subjects were asked to first complete the information-processing task. The subjects were then asked to complete the RISC and the PAS (as a measure of test-retest reliability). They were then debriefed using non-threatening terminology and everyday language and notified that the results of the study would be posted at the beginning of May. The procedure took approximately one hour per subject.

Results

The mean of the PAS scores was 5.50 , with a standard deviation of 5.10. A Pearson product moment correlation yielded a test-retest reliability of $\underline{r}(40)=.95, \underline{p}<.01$. 
A Pearson product moment correlation was conducted between the mass testing scores on the Beck Depression Inventory (BDI) and the PAS to ascertain whether the BDI and the PAS (measuring depression and a pleasure deficit, respectively) were sampling the same population. The scales do not appear to be sampling the same population, or similar constructs, $\underline{r}(280)=.04, \underline{p}>.05$. It should be noted that the BDI was only administered to female students. Reaction Time Data

The reaction time data were analyzed with a 2 (Type) $x$ 2 (Pattern) x 2 (Distraction) x 6 (PI) analysis of variance (ANOVA) to evaluate the effects of the four independent variables on response latency, with distraction, PI, and pattern serving as repeated measures.

The hypothesized crossover effect was observed with a significant three-way (Type $\times$ PI $\times$ Pattern) interaction, $\underline{F}(5,34)=4.20, \underline{p}<.004$. For ease of interpretation, Figure 1 shows this interaction as 2 two-way (PI $\times$ Pattern) interactions, one for each type.

\section{Insert Figure 1 about here}

Further analysis shows that there was a type by PI interaction which approached significance, $F(5,34)=2.25$, p>.06. There were significant differences between type at the 1s $P I, \underline{t}(1,38)=4.76, \underline{p}<.04$, and the 15s $\operatorname{PI}, \underline{t}(1,38)=$ 
$5.12, \underline{p}<.038$. Although pattern of presentation did not vary according to type, $\underline{F}(1,38)=.12, \underline{p}>.05$, Table 1 indicates that the pattern was in the hypothesized direction: The schizotypics' mean latencies were slower for the regular pattern than for the irregular pattern.

Insert Table 1 about here

When individual scores were graphed, 12 out of 20 schizotypic subjects (60\%) and 2 out of 20 nonschizotypics (10\%) exhibited a crossover effect. A chi-square analysis of these data was significant, $\mathrm{X}(1, \underline{\mathrm{N}}=40)=10.98 . \underline{\mathrm{p}}<.001$, supporting the crossover effect observed for the schizotypic subjects.

The distractor magnified the crossover effect with a significant Pattern x PI x Distraction interaction, $\underline{F}(5,34)$ $=5.66, \underline{p}<.003$, but did not vary with group membership as hypothesized by a four-way (Type $x$ Pattern $x$ PI $x$ Distraction) interaction, $\underline{F}(5,34)=1.75, \underline{p}<.05$. Again, although the interaction was not significant, the pattern of results was in the hypothesized direction.

Insert Figure 2 about here

Although a significant main effect was found for the distraction condition, $\underline{F}(1,38)=6.84, \underline{p}<.013$, of greater 
interest was the two-way (Type $x$ Distraction) interaction which reached statistical significance, $\underline{F}(1,38)=3.96$, p<.05. The distractor differentially affected the schizotypic and nonschizotypic subjects with the schizotypics showing greater susceptibility to the distraction. A t test between ratings of reported distraction and type yielded statistically significant differences: The schizotypics' mean rating (.8) was less than that of the normals $(2.90), \underline{t}(1,36)=5.83, \underline{p}<.05$ The reaction times of the subjects appear to mirror their subjective ratings of the distractibility of the distractor. Personality Measures

The mean of the RISC was 38.52 , with a standard deviation of 9.14. A Pearson product-moment correlation did not reveal a significant relationship between the RISC and the PAS, $\underline{r}(40)=-.24, \underline{p}>.05$. As can be seen from Table 2 , the point-biserial correlations between the RISC and the reaction time data did not yield a significant relationship.

Insert Table 2 about here

\section{Discussion}

The results of Experiment 1 replicate previous findings on the crossover effect of hypothetically schizotypic subjects. The schizotypic subjects in this experiment, like 
those in previous studies (Rosenbaum, Shore \& Chapin, 1988; Simons, MacMillan, \& Ireland, 1982), were found to exhibit an earlier RT crossover than control subjects. The crossover effect is similar to that found in schizophrenic subjects (Rodnick \& Shakow, 1940) and has been found to be unaffected by medication (Cromwell et al., 1979) or motivational manipulations (Steffy \& Galbraith, 1980). The early crossover effect for the schizotypics appears attributable to the fact that schizotypal subjects cross over earlier (at 1s PI vs 15S PI) than nonschizotypal subjects. Although the interaction between type and pattern was not significant, it was in the hypothesized direction: The schizotypics' RT latencies to predictable PIs became slower than their RT latencies to unpredictable PIs as the interval increased.

The inability of the schizotypics to take advantage of the predictability of the fixed pattern at longer PIs suggests a deficit in maintaining conscious capacity-loading attention compared to the nonschizotypics. According to Posner (1982), it is under conditions of stimulus predictability that conscious attention should benefit performance by facilitating rapid processing of the expected stimulus. The schizotypics' inability to profit from predictability does not fully account for the phenomenon of the crossover effect, because the crossover phenomenon involves not just equal RT, but actually slower RT under 
predictable, as compared to unpredictable, long PIs.

Therefore, based on Shakow's (1961) hypothesis that schizophrenic attentional deficit is, in part, a function of orienting to distracting, irrelevant stimuli, as opposed to the task-relevant stimuli, it was hypothesized that a distractor would magnify the effect of the schizotypics' crossover. Although the crossover in the distraction condition was not significant for group, the results were in the hypothesized direction: The schizotypes initially failed to take advantage of the fixed PI.

The mean subject ratings of the distraction, as well as verbalizations during the debriefing that the distraction was not "distracting," indicate that the distraction may have not had an adequate loading to elicit a differential crossover effect for group membership. As Nuechterlein and Dawson (1986) noted in a review of the literature on information processing across the schizophrenic continuum, higher processing loadings are required to tap attentional dysfunction in asymptomatic individuals identified as vulnerable to a schizophrenic episode.

The distraction affected both schizotypal and nonschizotypal subjects in that both groups evidenced delayed latencies. Although not significant, the schizotypal subjects' latencies were slower in the distraction condition than the nondistraction condition. The RISC was included to assess the divergent 
validity of the PAS. Although there was not a significant relationship, the relationship between the scales was in the hypothesized negative direction. The negative correlation is consistent with the notion that the RISC and the PAS may measure behavioral signs that are independent. The RISC was designed to assess cognitive content, which is supported by the lack of relationship with the reaction time data. Since both scales were designed to assess the same underlying construct, proneness to a schizophrenic episode, but measure independent behavioral signs, the scales may serve a useful discriminating function when employed together. 
Experiment 2

Experiment 2 was designed to address the issue that the distraction in Experiment 1 may not have had an adequate loading to elicit the crossover effect. The procedure employed in Experiment 2 was almost identical to that of Experiment 1, with the exception that the distraction employed consisted of a story read by a male's voice. It was hypothesized that, as in Experiment 1, a three-way interaction (Type $x$ PI $x$ Pattern) would yield a crossover effect. As an extension of this finding, it was hypothesized that the distractor, as a more meaningful stimuli requiring more complex processing, would maximize the crossover effect through a four-way (Type x PI x Pattern $\mathbf{x}$ Distraction) interaction in the distraction condition.

\section{Method}

\section{Subjects}

Approximately 280 students (ages 18 and older)

completed the abbreviated version of the PAS. Subject selection differed from Experiment 1 in that students who scored 1 to 1 1/2 standard deviations above and below the mean (as opposed to 2 standard deviations) were eligible for the study. The Experimenters could not adhere to Chapman et al.'s (1976) criterion in this study due to the unavailability of subjects. The mean of the PAS scores from the spring mass testing was 4.54 , with a standard deviation of 3.12. The scores were comparable to the fall mass 
testing.

students were contacted by phone by this experimenter and asked to participate in a study about personality and attention. Of the 70 students who were contacted, 40 agreed to participate in the study. Due to a disk error resulting in failure to record data, 6 subjects' data were not usable, leaving 16 subjects in the hypothetically schizotypal group and 17 subjects in the non-schizotypal group. students participating in the study received one hour of credit toward completion of a course research requirement.

\section{Apparatus}

An IBM computer programmed with Rodnick and Shakow's RT paradigm was employed as in Experiment 1, with the exception of the programming of the auditory distractor.

The auditory distractor was a story by 0 . Henry, read by a male's voice, delivered binaurally through earphones that were attached to a sony tape recorder. The Experimenter turned on the tape recorder to which the subject's earphones were attached after one set of regular and irregular series of trials. The RT program then proceeded as in Experiment 1 with the story as the auditory distractor during the second set of regular and irregular series of trials.

Personality measurements

The personality measurements used were identical to those in Experiment 1. 


\section{Procedure}

The design and procedure were identical to those of Experiment 1, except that after one set of regular and irregular series of trials, the subject was instructed to refer to the Experimenter. The Experimenter then turned on the tape recorder and the program proceeded as in Experiment 1 .

\section{Results}

The mean of the PAS scores was 3.57 , with a standard deviation of 3.60. These mean scores are lower than the scores in Experiment 1. A Pearson product moment correlation yielded a test-retest reliability of $\underline{r}(33)=$ $.89, \underline{p}<.01$

A Pearson product moment correlation was conducted between mass testing scores on the BDI and the PAS to ascertain whether the BDI and the PAS were sampling the same population. There was no significant relationship, $\underline{\mathbf{r}}(125)=$ $.002, \underline{p}>.05$. It is significant to note that the BDI was only administered to female students.

\section{Reaction Time Data}

As in Experiment 1, the reaction time data were analyzed with a 2 (Type) $\times 2$ (Pattern) $\times 2$ (Distraction) $\times 6$ (PI) analysis of variance (ANOVA) to evaluate the effects of the four independent variables on response latency, with distraction, preparatory interval, and pattern serving as repeated measures. 
As in Experiment 1, in general, reaction times were slower when the PI was irregular than they were under regular PI conditions, $\underline{F}(1,31)=7.22, \underline{p}<.01$. There was not a significant crossover effect, as the Pattern $\times$ PI interaction did not reach significance, $\underline{F}(5,27)=1.31$, $\underline{p}$ $>.05$. The predicted three-way (Type $x$ Preparatory Interval $x$ Pattern) interaction was not obtained as in Experiment 1, $\underline{F}(5,27)=1.32, \underline{p}>.28$

The distractor was changed from a non-meaningful distractor to a meaningful story in order to elicit the hypothesized crossover effect for the schizotypal subjects (Type $\mathrm{x}$ Pattern $\mathrm{x}$ PI $\mathrm{x}$ Distraction). As might be expected, since the general crossover effect (Pattern $x$ PI) was not obtained, the four-way (Type $\times$ Pattern $\times$ PI $\times$ Distraction) interaction did not reach statistical significance, $\underline{F}(5,27)$ $=.74, \underline{p}>.05$. Essentially there was not a crossover effect for the distractor to magnify.

A two-way (Type $\mathrm{x}$ Distraction) interaction reached statistical significance, $\underline{F}(1,31)=6.26, \underline{p}<.02$. Again, the distraction had a significantly differential effect on the schizotypic subjects than the nonschizotypic subjects. Interestingly, Table 2 shows that the schizotypic subjects' mean latencies were faster in the distraction condition than in the nondistraction condition, with the nonschizotypic subjects exhibiting the reversed effect. Although the mean ratings of reported distraction 
were higher than those in Experiment 1 (2.90 vs. 3.47 for schizotypics; .8 vs. 4.50 for normals), a $t$ test between ratings of reported distraction and type did not yield statistically significant differences: The schizotypics' mean rating ( 3.47$)$ was similar to that of the normals' $(4.50), \underline{t}(1,31)=1.56, \underline{p}>.13$.

An analysis of variance was conducted on the reaction time data as a function of task. No significant differences were found for either pattern, PI, or distraction. Personality Measures

A Pearson product moment correlation did not reveal a significant relationship between the RISC and the PAS, $\underline{r},(33)=-.17, \underline{p}>.05$. Point biserial correlations between the RISC and the reaction time data are presented in Table 3. Correlations between the RISC scores and RT were nonsignificant.

\section{Discussion}

The crossover effect evidenced by the schizotypic subjects in Experiment 1 was not present in Experiment 2 . It is suspected that the sample may have contained false positives due to the change in criterion from 2 standard deviations above the mean to $11 / 2$ standard deviations above the mean. The mean of the PAS scores were lower in this experiment than Experiment 1. As Raulin and Lowrie note (1990), the method of selecting samples of high-risk cases can directly influence results, and therefore the 
conclusions that can be drawn from behavioral high-risk studies.

As would be expected, since the triple (Type $x$ PI $x$ Pattern) interaction was not replicated, there was no evidence of the distractor magnifying a crossover effect within the schizotypal condition. The mean subject ratings of reported distraction $(1.9$ and 3.98 on a scale from 1 to 10) suggests that the distraction may not have had an adequate loading to elicit the hypothesized attentional deficit in asymptomatic college students.

Interestingly, the distractor had a differential effect on the schizotypal and nonschizotypal subjects. The schizotypal subjects' mean latencies were faster in the distraction condition than the nondistraction condition, whereas the nonschizotypals' mean latencies were faster in the nondistraction condition than the distraction condition. It is difficult to explain this finding other than to speculate on the presence of false positives in the sample.

As in Experiment 1, correlations between the PAS and the RISC were not significant, indicating that the PAS and the RISC measure different constructs. As shown in Table 3, the correlations between the RISC and RT scores are comparable to those in Experiment 1. 
General Discussion

The present study was designed to investigate whether subjects identified on the basis of high scores on the PAS would evidence a reaction-time crossover under conditions known to reliably elicit this pattern from schizophrenic patients. Based on Shakow's (1961) theory, the present study also employed a distractor designed to magnify the RT crossover effect. The hypothesized relationship between pattern and PI for schizotypics and normals was supported in Experiment 1, but these results were not supported or extended in Experiment 2 .

The results of Experiment 1 supported the crossover effect, indicating that deficits may be related to a reduction in the processing capacity that is available for task-relevant cognitive operations in individuals identified as vulnerable to a schizophrenic episode by the PAS. Such results demonstrating the RT crossover among asymptomatic adults are consistent with the use of RT crossover as a vulnerability marker (Zubin \& Spring, 1978) independent of clinical symptoms.

Based on Shakow's theory, a distraction employed with the RT paradigm was expected to extend these results by magnifying the crossover effect, thereby supporting the theory that individuals identified as vulnerable orient more to task-irrelevant stimuli, as evidenced by slower latencies in the fixed PIs. The results were in the hypothesized 
direction, but not statistically significant. It was suspected that the distraction may not have had an adequate loading.

Therefore the focus of Experiment 2 was to employ a distractor with a higher processing load. The findings of Experiment 2 did not support the crossover effect in either the nondistraction or the distraction condition. The absence of the crossover effect may be due to subject selection procedures.

Another alternative to the absence of the crossover effect in the distraction condition may be due to the type of processing the distraction required. Information processing may be roughly divided into active (controlled) and passive (automatic) operations (Schneider \& Shiffrin, 1977). Active processes, such as rote rehearsal, coding, and some forms of memory search, must be carried out in a serial fashion and are limited in capacity. It has been observed that for many schizophrenics, the presence of salient, extraneous stimuli disrupts these controlled processes (Oltmanns, 1978).

Passive operations may not be so vulnerable to extraneous stimuli. The deterioration in active processing of relevant material may not be due to orienting to taskirrelevant stimuli, as hypothesized by Shakow (1961), but to less efficient handling of relevant stimuli. This study utilized distractors that tapped passive processes as 
opposed to active processes, which may not be as vulnerable to irrelevant stimuli.

If attentional dysfunction is in fact a result of interference of active processes by extraneous stimuli, what can be said of the RT crossover which is purported to tap the passive processes of sustained attention? Is the RT crossover an artifact of planned variance? Further research is needed to investigate these questions.

Evidence of the crossover effect among schizotypic subjects is not conclusive. There are several reasons, however, why this should not be construed as evidence against the hypothesized high-risk status of PAS-identified subjects. First the initial crossover effect was obtained. Second, the schizotypal crossover pattern in the distraction condition was in the hypothesized direction. Third the data in the distraction condition did suggest that absolute RTs obtained from the schizotypics were slower. While this difference was not statistically significant, it was consistent with previously reported differences (Simons et al., 1982; Rosenbaum et al., 1988). Finally, data obtained from other studies of schizotypal subjects support the high-risk hypothesis (Edell \& Chapman, 1979; Simons, MacMillan, \& Ireland, 1982; Rosenbaum, Shore, \& Chapin, 1988).

In summary, the present reaction-time data do provide some additional validation for the Physical Anhedonia Scale 
as a measure of RT crossover. In addition, some interesting questions are raised as to what subsystem of attention the RT paradigm is tapping. More research is needed employing Rodnick and Shakow's (1940) paradigm with manipulation of distraction conditions that require active processing. While the ultimate test of the vulnerability hypothesis rests in longitudinal study, relevant evidence is cumulative and often indirect. It is true of clinical schizophrenia that no single subject characteristic assures group membership, and this is no less true of these subjects. The RT crossover is consistent with a high-risk hypothesis and provides clear evidence that PAS-identified schizotypics merit further investigation. 
References

Bellissimo, A., \& Steffy, R. A. (1972) . Redundancyassociated deficit in schizophrenic reaction time performance. Journal of Abnormal Psychology, 80, 299-307. Bellissimo, A., \& Steffy, R. A. (1975). Contextual influences on crossover in the reaction time performance of schizophrenics. Journal of Abnormal Psychology, 84, $210-220$

Chapman, L. J., Chapman, J. P., \& Raulin, M. L. (1976) . Scales for physical and social anhedonia. Journal of Abnormal Psychology, 85, 374-382.

Chapman, L. J., Chapman, J. P., \& Raulin, M. L. (1978). Body-image aberration in schizophrenia. Journal of Abnormal Psychology, 87, 399-407.

DeAmicis L. A., \& Cromwell, R. L. (1979). Reaction time cross-over in process schizophrenic patients, their relatives, and control subjects. Journal of Nervous and Mental Disease, 167, 593-600.

Drewer, H. B., \& Shean, G. D. (1990, April) . Relationship between self-report measures of schizotypy and cognitive performance. Poster presented at the southwestern Psychological Association, Dallas, TX.

Eckblad, M., \& Chapman, L. J. (1983). Magical ideation as an indicator of schizotypy. Journal of consulting and Clinical Psychology, 51, 215-225.

Edell, W. S., \& Chapman, L. J. (1978) . Anhedonia, 
perceptual aberration, and the Rorschach. Journal of Consulting and clinical Psychology, 47, 377-384. Haberman, M. C., Chapman, L. J., Numbers, J. S., \& McFall, R. M. (1979). Relation of social competence to scores on two scales of psychosis proneness. Journal of Abnormal Psychology, 88, 675-677.

Knight, R. G., Youard, P. J., \& Wooles, I. M. (1985). Visual information-processing deficits in chronic schizophrenic subjects using tasks matched for discriminating power. Journal of Abnormal Psychology, 94, $454-459$.

Lawson, J. S., McGhie, A., \& Chapman, J. (1967). Distractibility in schizophrenia and organic cerebral disease. British Journal of Psychiatry, 113, 527-535. Lowrie, G. S., \& Raulin, M. L. (1990, April). Search for schizotypic and nonschizotypic taxonomies in a college population. Paper presented at the meeting of the Eastern Psychological Association, Philadelphia, PA.

Meehl, P. E. (1962). Schizotaxia, schizotypy, schizophrenia. American Psychologist, 17, 827-838. Ohman, A., \& Nordby, H. (1986). Orienting and schizophrenia: Stimulus significance, attention, and distraction in a signaled reaction time task. Journal of Abnormal Psychology, 95, 326-334. Oltmanns, T. F. (1978). Selective attention in schizophrenic and manic psychosis: The effect of 
distraction on information processing. Journal of Abnormal Psychology, 87, 212-225.

Oltmanns, T. F., Ohayon, J., \& Neale, J. M. (1978). The effect of anti-psychotic medication and diagnostic criteria on distractibility in schizophrenia. Journal of Psychiatric Research, 14, 81-91.

Posner, M. I. (1982). Cumulative development of attentional theory. American Psychologist, 37, 168-179. Rodnick, E. H., \& Shakow, D. (1940). Set in the schizophrenic as measured by a composite reaction time index. American Journal of Psychiatry, 97, 214-225. Rosenbaum, G., Shore, D. L., \& Chapin, K. (1988). Attention deficit in schizophrenia and schizotypy: Marker versus symptom variables. Journal of Abnormal Psychology, 97, 41-47.

Rust, J. (1989). The handbook of Rust Inventory of Schizotypal Cognitions. London: Harcourt Brace Jovanovich.

Shakow, D. (1961). Segmental set: A theory of the formal psychological deficit in schizophrenia. Archives of General Psychiatry, $6,17-31$.

Schneider, W., \& Shiffrin, R. M. (1977). Controlled an automatic human information processing: I. Detection, search, and attention. Psychological Review, 81, 1-66. Simons, R. F. (1981). Electrodermal and cardiac orienting in psychometrically defined high risk subjects. 
Psychiatry Research, $\underline{4}, 347-356$.

Simons, R. F. (1982). Physical anhedonia and future psychopathology: A possible electrocortical continuity. Psychophysiology, 19, 433-441.

Simons, R. F., MacMillan, F. W. III, \& Ireland, F. B. (1982). Reaction-time crossover in preselected schizotypic subjects. Journal of Abnormal Psychology, 91, $214-225$.

Spring, B., Nuechterlein, K. H., Sugarman, J., \& Matthysse, S. (1977). The "new look" in studies of schizophrenic attention and information processing. Schizophrenia Bulletin, $\underline{3}, 470-481$.

Steffy, R. A., \& Galbraith, K. J. (1980). Relation between latency and redundancy-associated deficit in schizophrenic reaction time performance. Journal of Abnormal Psychology, 89, 419-427.

Strauss, M. E., Bohannon, W. E., Kaminsky, M. J., \& Kharabi, F. (1979). Simple reaction time crossover occurs in schizophrenic outpatients. Schizophrenia Bulletin, $\underline{5}$, $612-614$

Zahn, T. P., Rosenthal, D., \& Shakow, D. (1963). Effects of irregular preparatory intervals on reaction time in schizophrenia. Journal of Abnormal and Social Psychology, 67, 44-52.

Zubin, J., \& Spring, B. (1977). Vulnerability: A new view of schizophrenia. Journal of Abnormal Psychology, 86, 
103-126. 
Table 1

Mean Reaction Time scores as a Function of Type,

Distraction, and Pattern for Experiment 1

Condition

Type Distraction Nondistraction

Schizotypal

Irregular

Regular

Nonschizotypal

Irregular

Regular
478.41

497.44

459.37

446.07

424.52

439.83
449.16

415.02

482.61

426.62

428.72

424.52 
Table 2

Mean Reaction Time scores as a Function of Type,

Distraction, and Pattern for Experiment $\underline{2}$

Condition

Type Distraction Nondistraction

$\begin{array}{ccc}\text { Schizotypal } & 417.05 & 455.57 \\ \text { Irregular } & 428.60 & 381.35 \\ \text { Regular } & 405.49 & 429.79 \\ \text { Nonschizotypal } & 433.38 & 383.39 \\ \text { Irregular } & 464.56 & 409.70 \\ \text { Regular } & 402.21 & 357.09\end{array}$


Table 3

Point Biserial Correlations between Reaction Time

Scores and the RISC for Experiments 1 and $\underline{2}$

Experiment

Condition

1

2

Distraction

Regular

.03

.28

Irregular

.29

.21

Nondistraction

Regular

Irregular
.16

.29
.28

.24 
Figure 1. Reaction time performance as a function of Pattern and Preparatory Interval (PI) for schizotypal and nonschizotypal subjects in the nondistraction condition. 


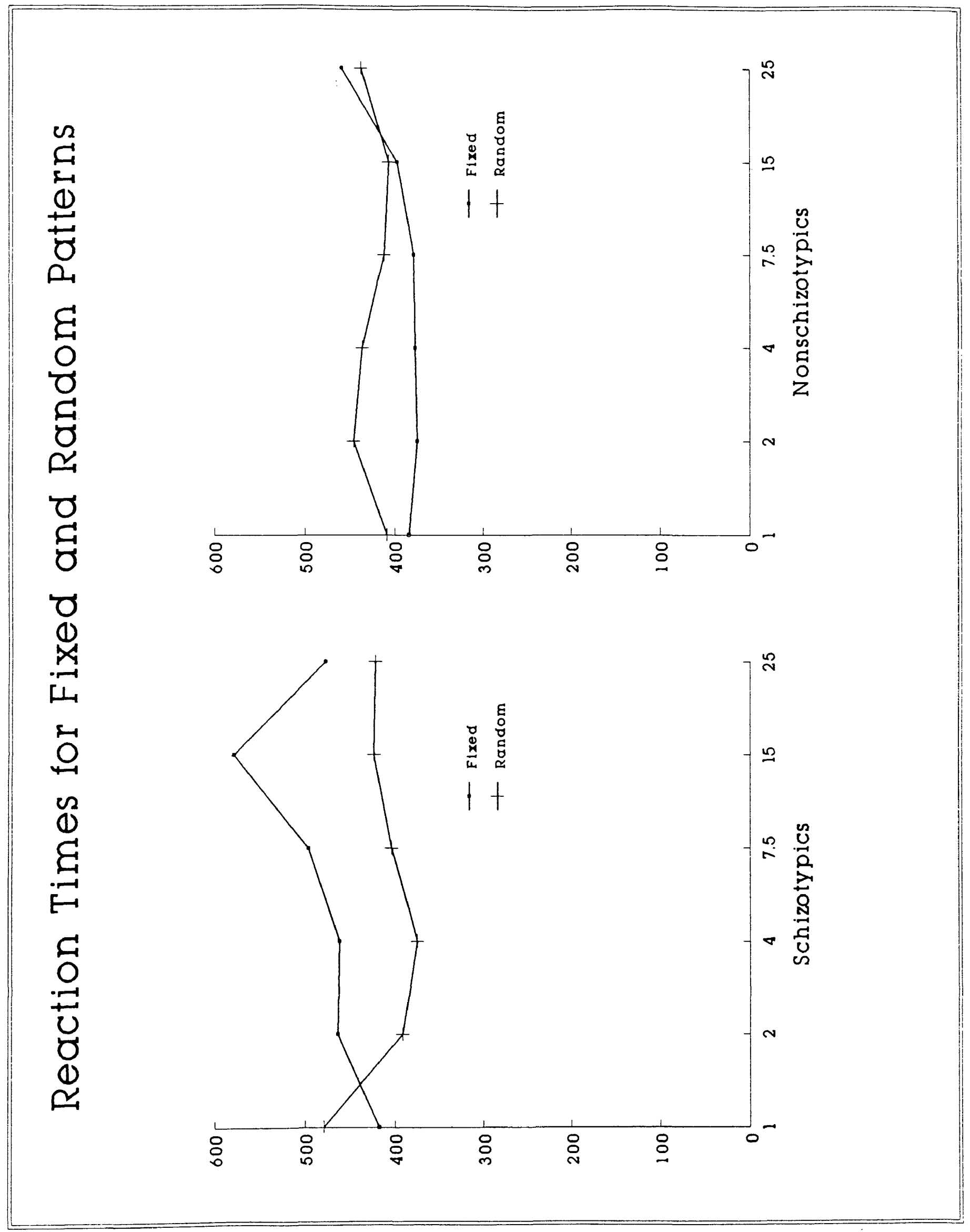


Figure 2. Reaction time performance as a function of Pattern and Preparatory Interval for schizotypics and nonschizotypics in distraction condition. 

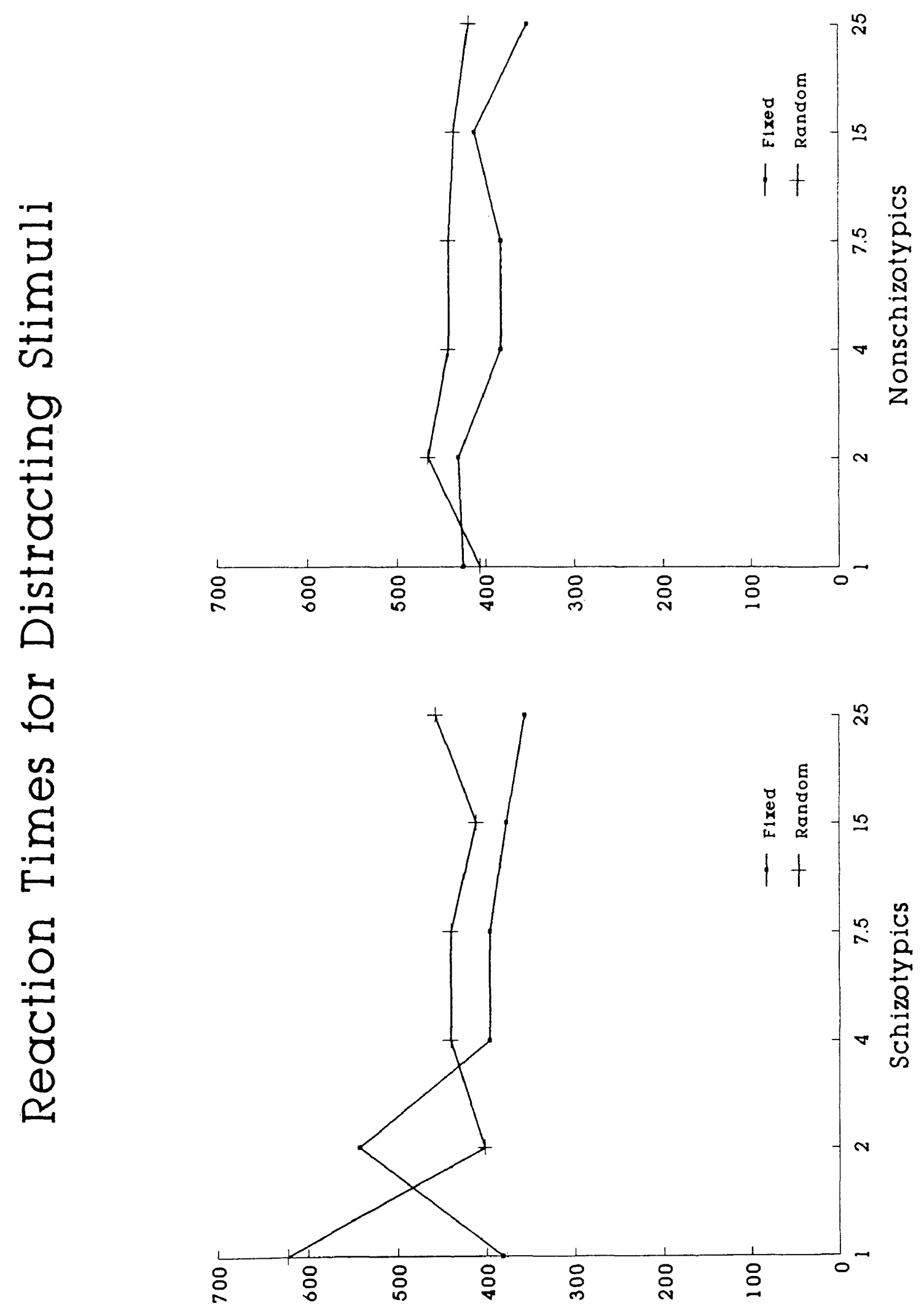
Chapman scale

Appendix A

1. When I'm feeling a little sad, singing has often Made me feel happier.

2. Dancing, or the idea of it, has always seemed dull to me.

3. When eating a favorite food,

I have often tried to eat slowly

to make it last longer.

4. I have always found organ music

dull and unexciting.

5. I have often enjoyed the feel

of silk, velvet, or fur.

6. I have had very little fun

from physical activities

like walking, swimming, or sports.

7. I have sometimes enjoyed feeling

the strength in my muscles.

8. I have seldom enjoyed any kind of sexual experience.

9. I have always loved having

my back massaged.

10. On hearing a good song, I have seldom wanted to sing along with it. $T$ F

11. Trying new foods is something

I have always enjoyed.

12. I have always hated the feeling of exhaustion that comes from vigorous activity.

13. When I have seen a statue, I have had the urge to feel it. 
14. The color that things

are painted has seldom mattered

to me.

T $\quad$ F

15. I have always had a number

of favorite foods.

T F

16. The sound of rustling leaves

has never much pleased me.

T $\quad F$

17. When I have walked by a bakery,

the smell of fresh

bread has often made me hungry.

T $\quad F$

18. Sunbathing isn't really more fun than lying down indoors.

T $\quad \mathrm{F}$

19. I have often enjoyed

receiving a strong, warm

handshake.

T $\quad \mathrm{F}$

20. There just are not many things

that I have ever really

enjoyed doing.

T $\quad \mathrm{F}$

21. I have often found walks to

be relaxing and enjoyable.

T $\quad F$

22. I have never found a

thunderstorm exhilarating.

T $\quad \mathbf{F}$

23. The sound of the rain falling

on the roof has made me feel

snug and secure.

T $\quad \mathbf{F}$

24. Sex is okay, but not as much

fun as most people claim it is. $T$ T

25. I like playing and petting

soft little kittens

or puppies.

T $\quad$ F 
Appendix B

1. On a scale of 1 (least) to 10 (most), rate how distracting you found the noise that you heard during the computer task.

$\begin{array}{llllllllll}1 & 2 & 3 & 4 & 5 & 6 & 7 & 8 & 9 & 10\end{array}$

least most 


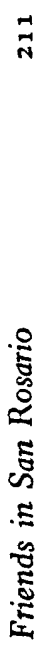

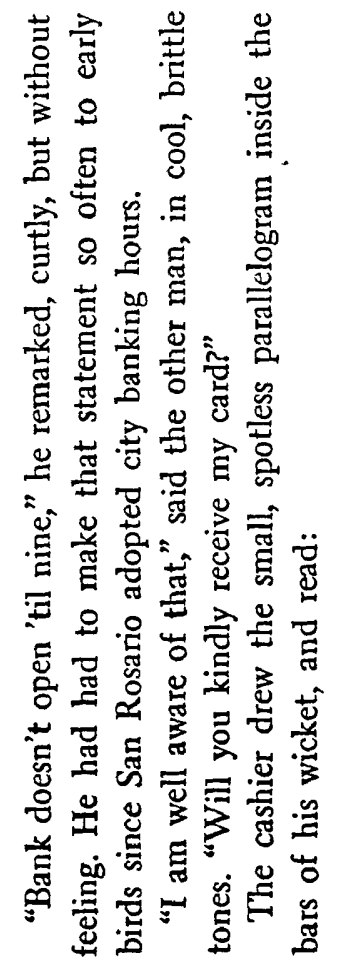$$
\text { 落 }
$$

$\dot{*}=\Xi \pm$

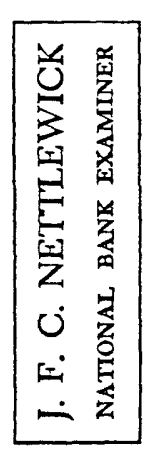

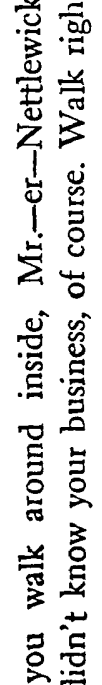

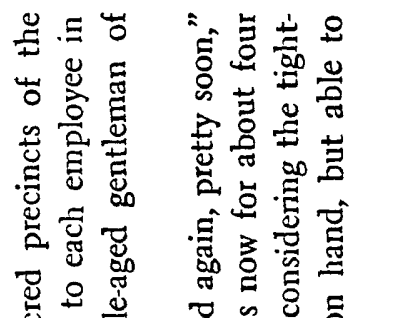

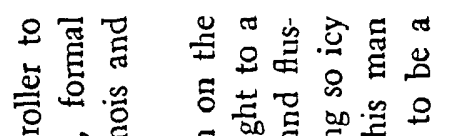

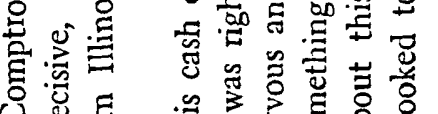

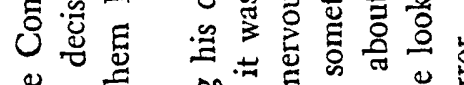

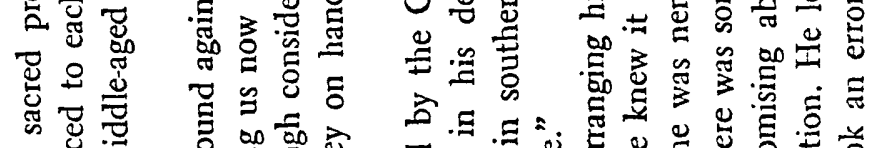

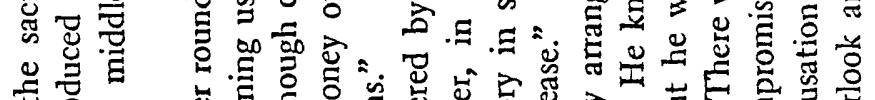

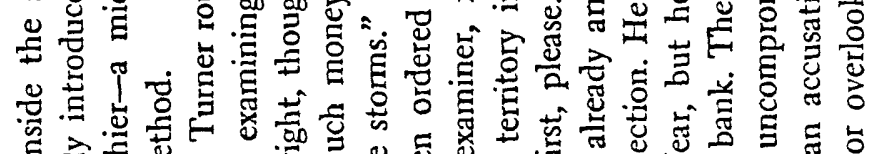
.

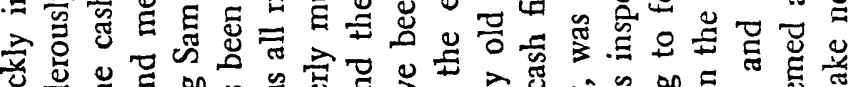

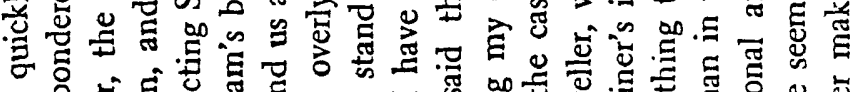

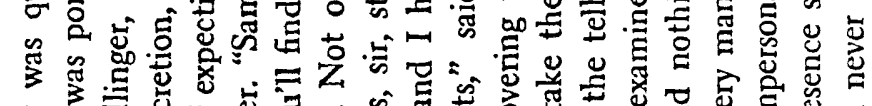

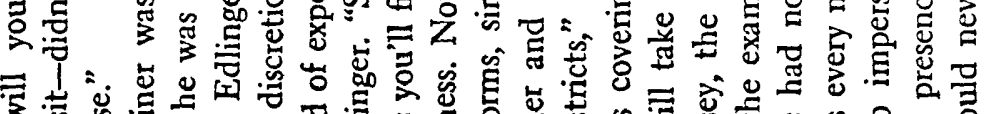

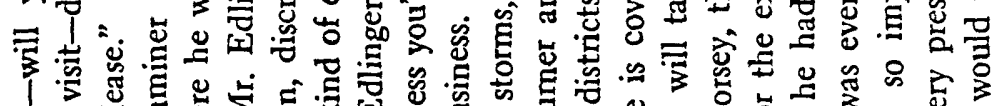

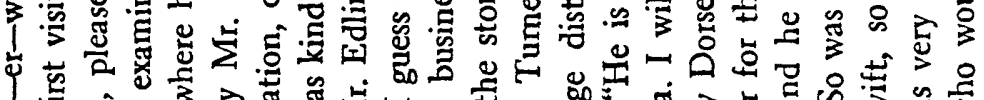

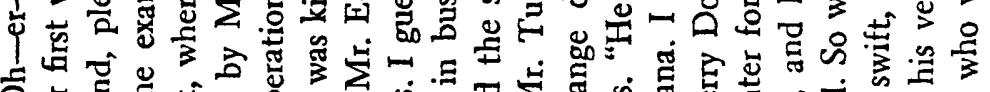

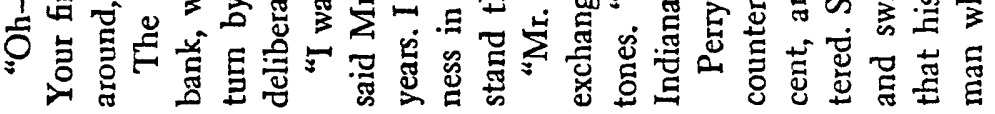

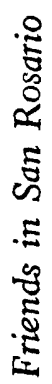

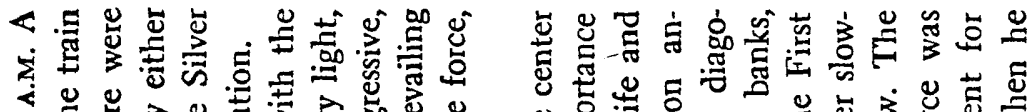

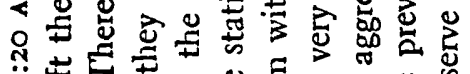

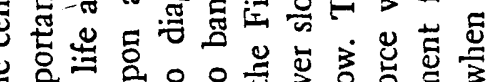

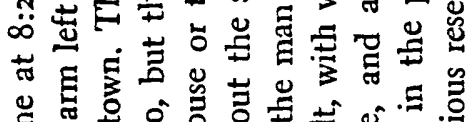

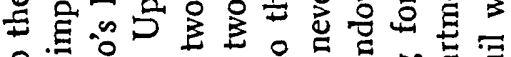

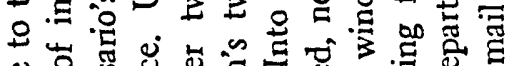

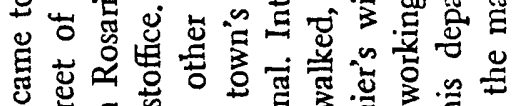

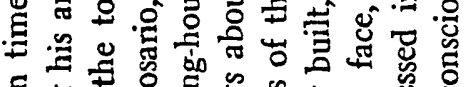

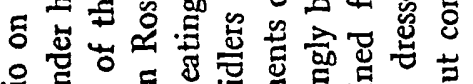

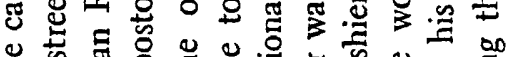

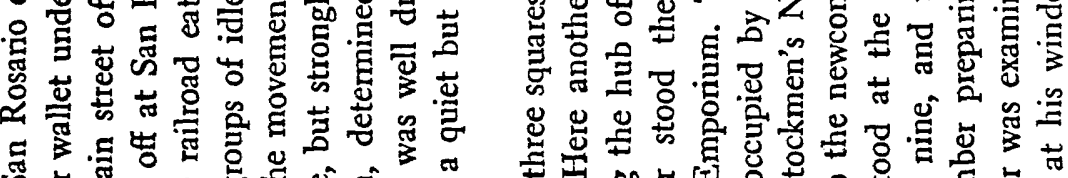

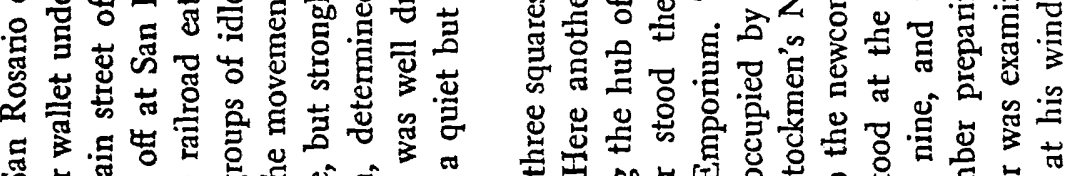

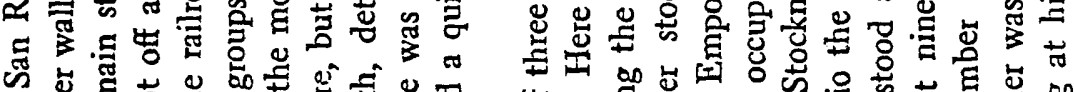

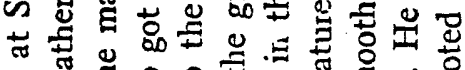

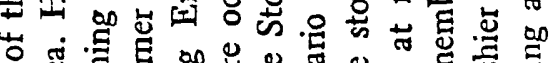

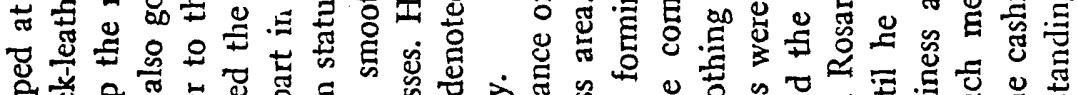

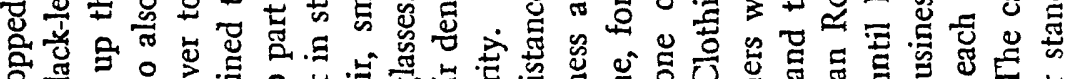

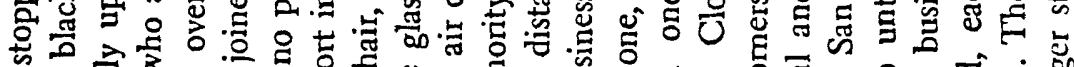

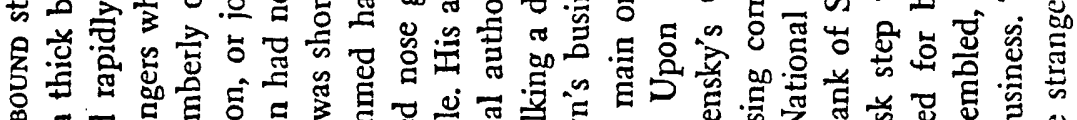

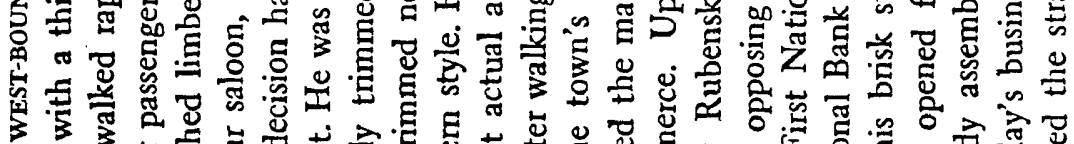

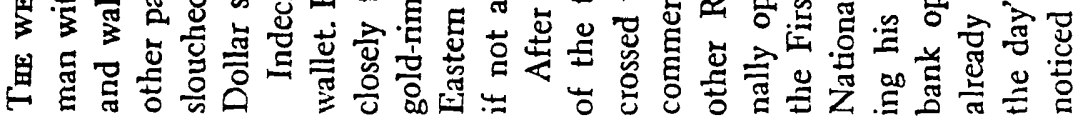




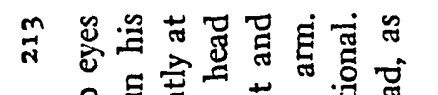

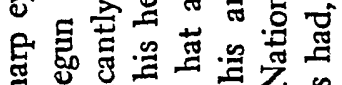

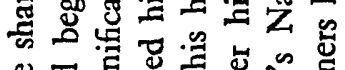

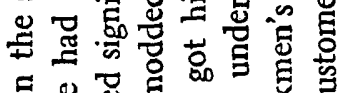

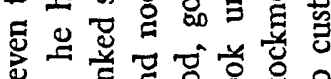

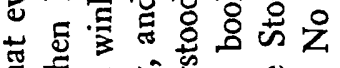

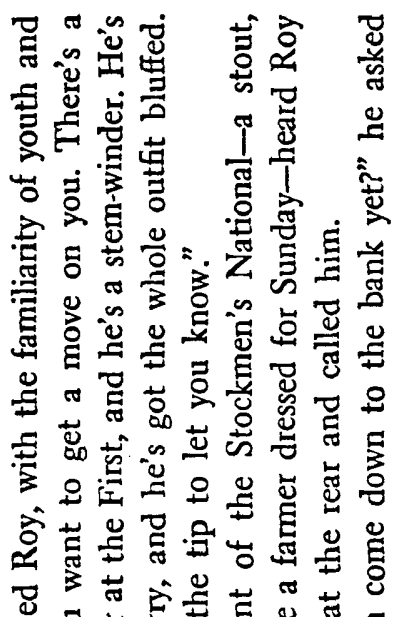

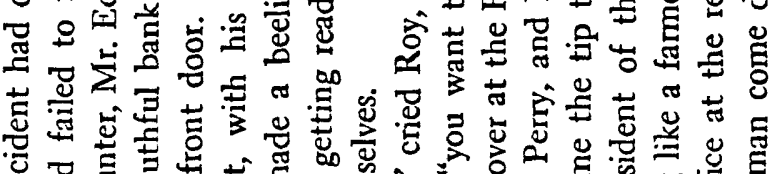

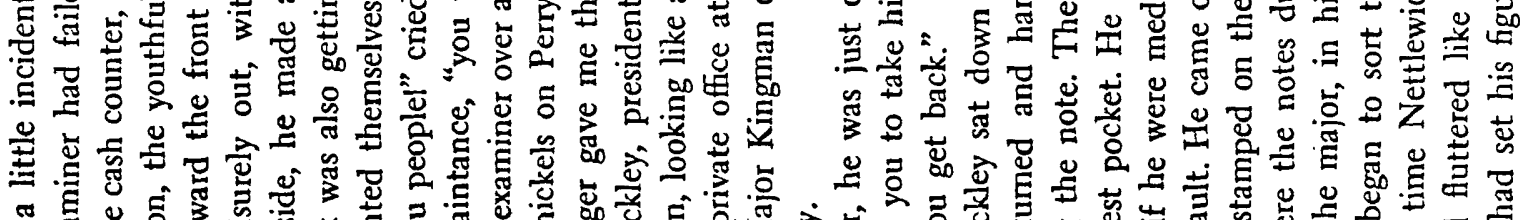

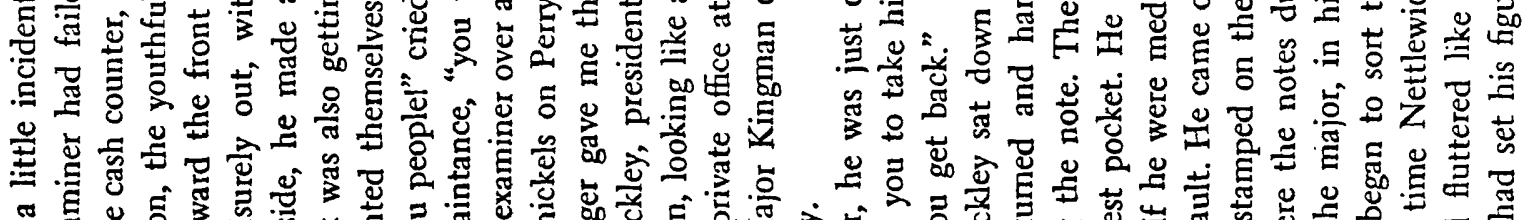

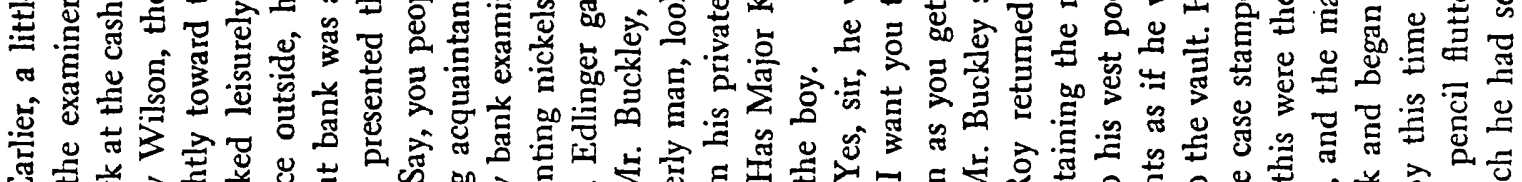

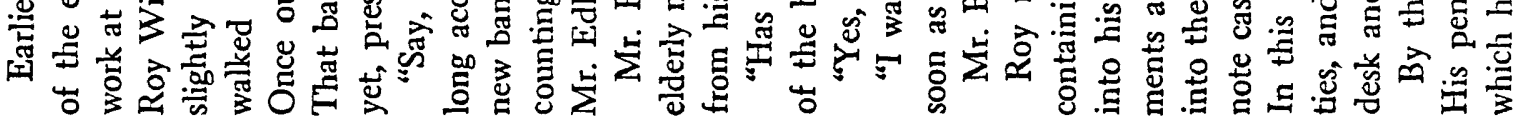

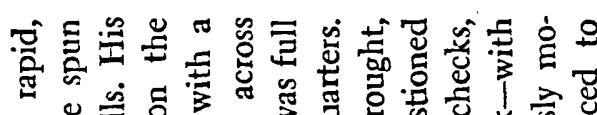

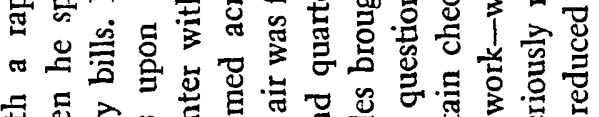

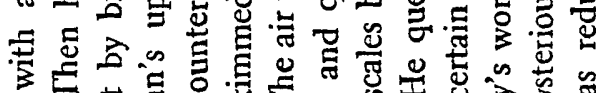

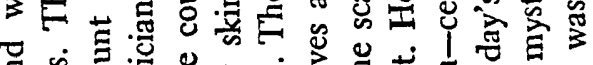

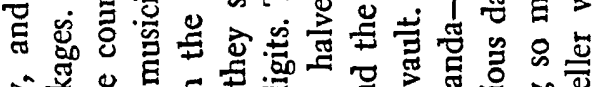

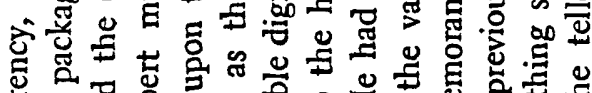

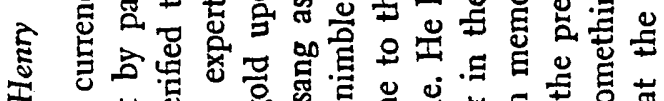
00 $\div$ $\stackrel{8}{8}$

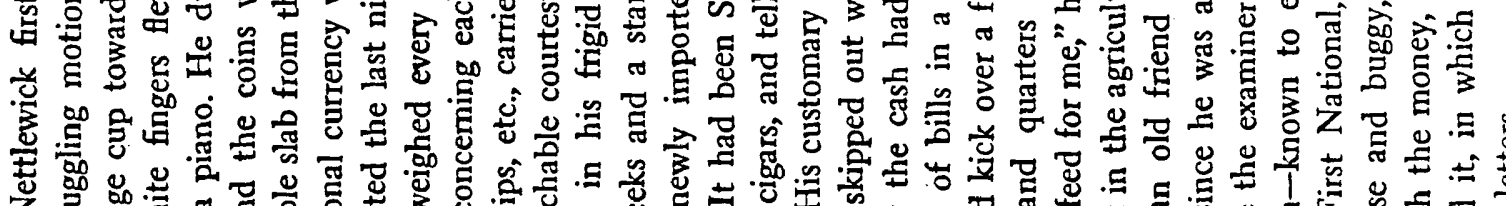

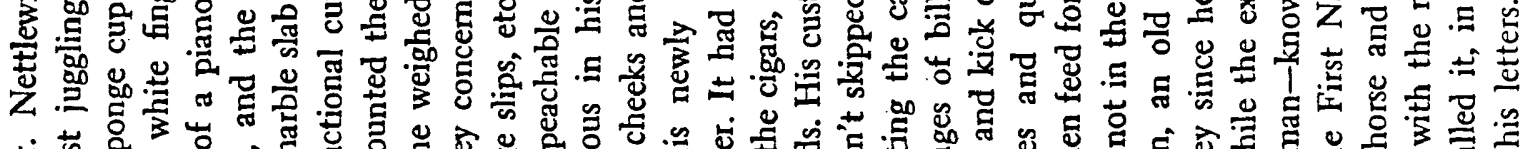

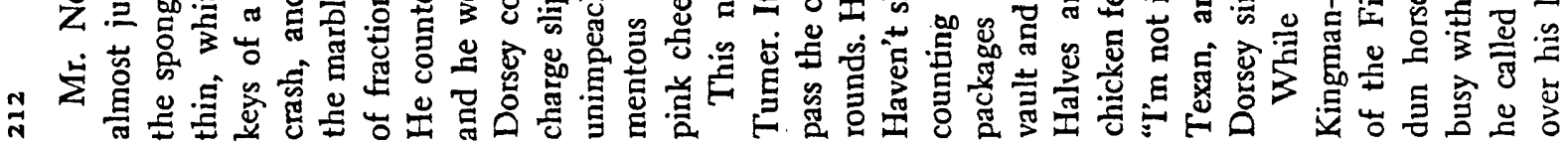

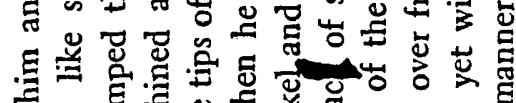

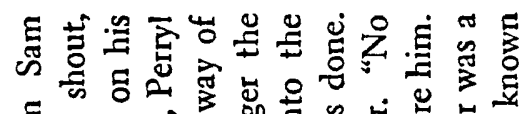

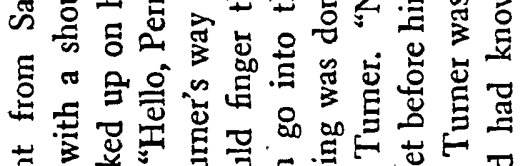

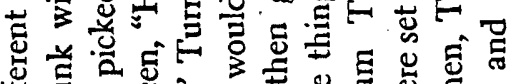

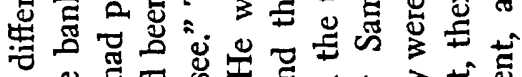

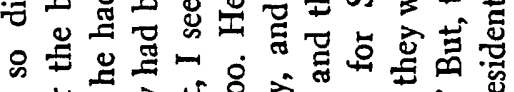

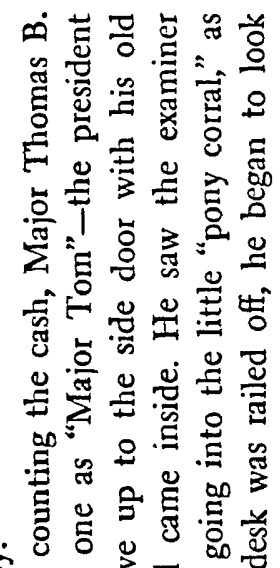

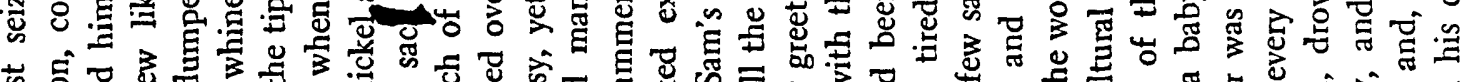




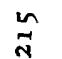

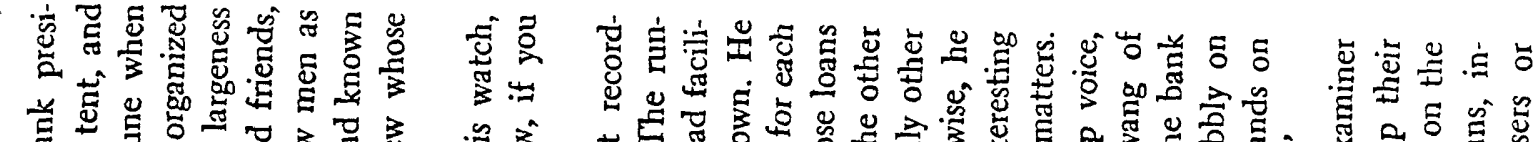
今

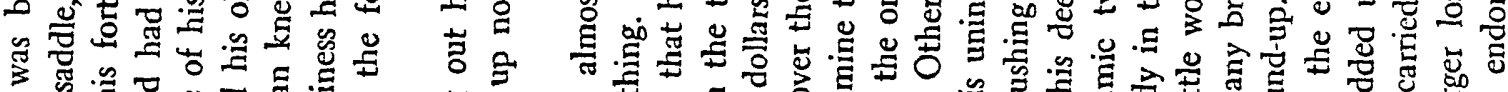

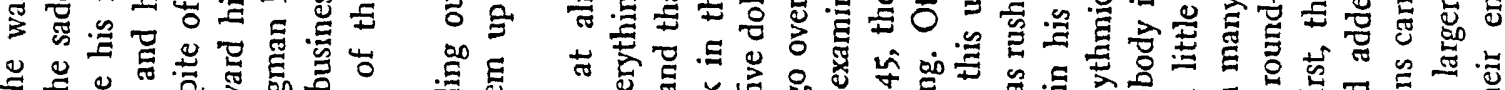

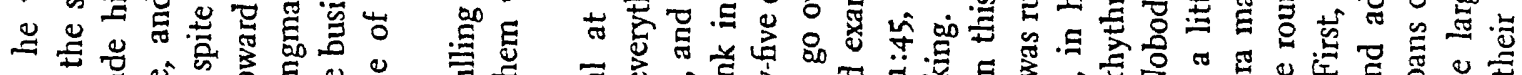

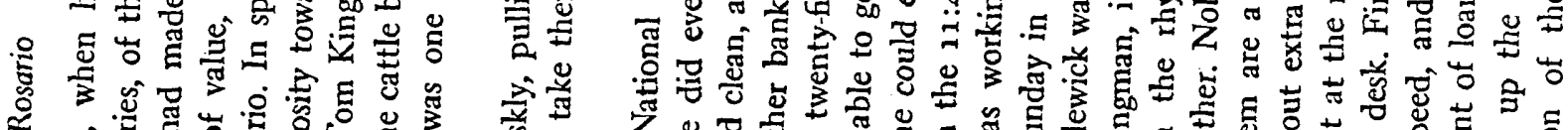

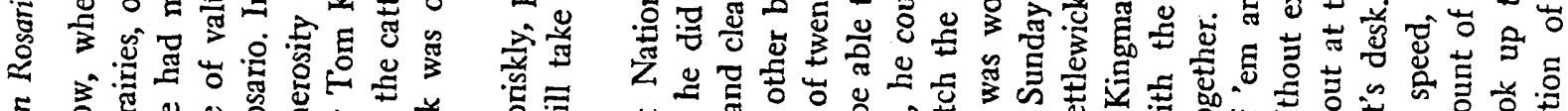
5

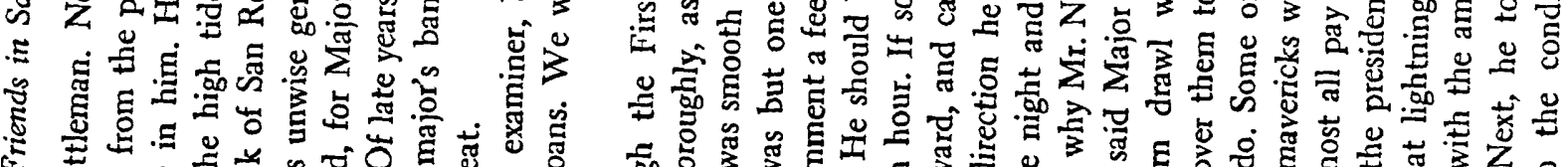
है

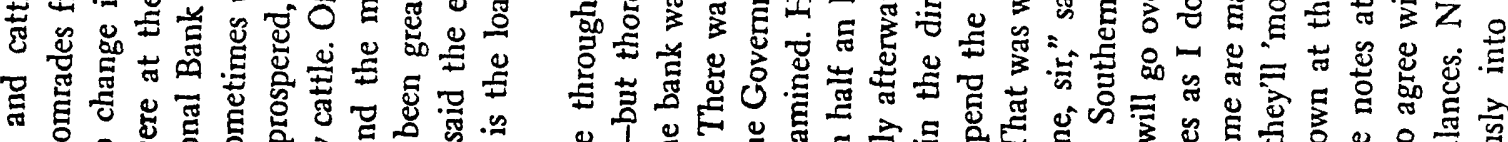

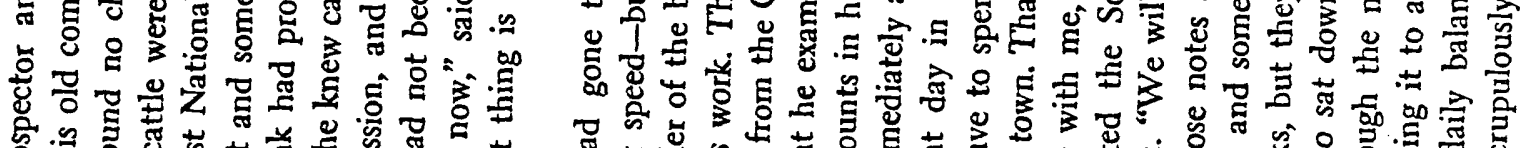

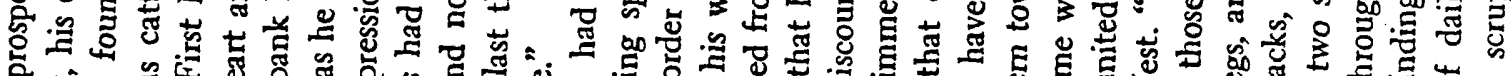

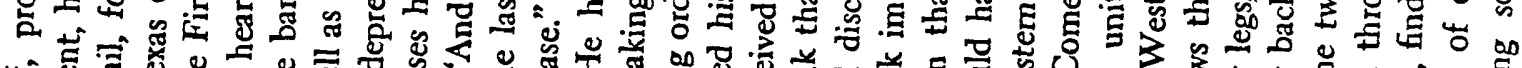

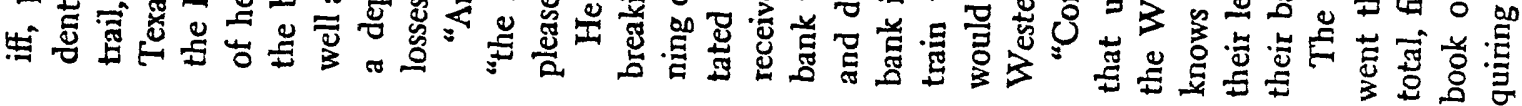

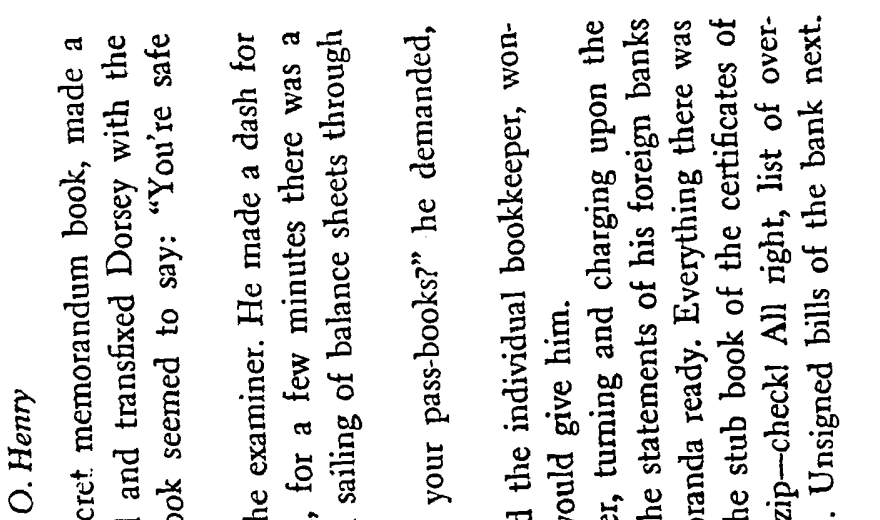

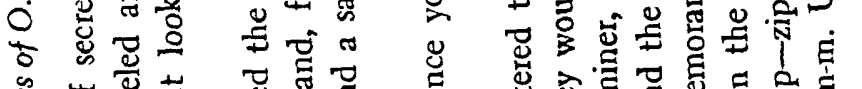

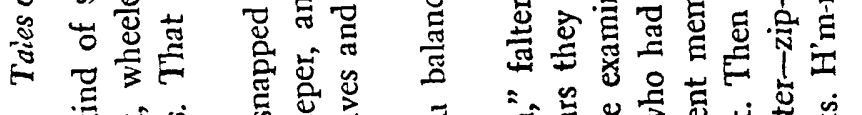

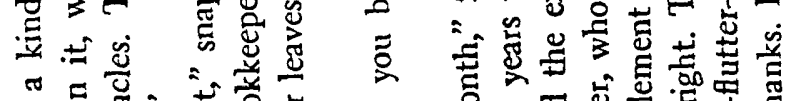

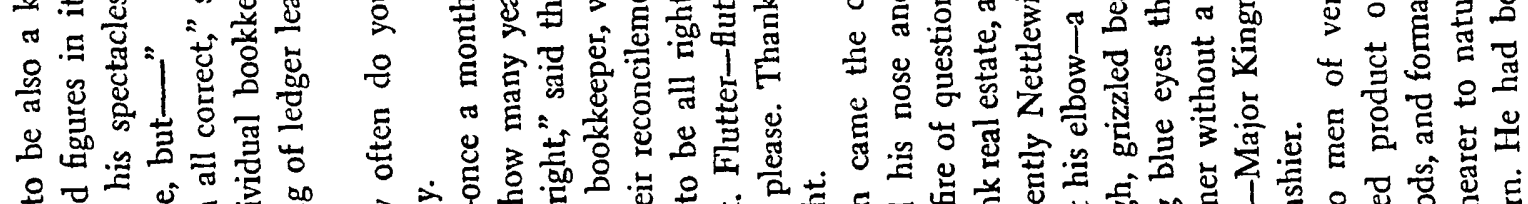

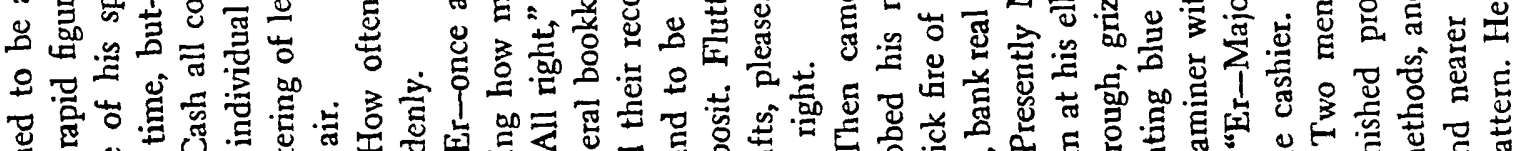

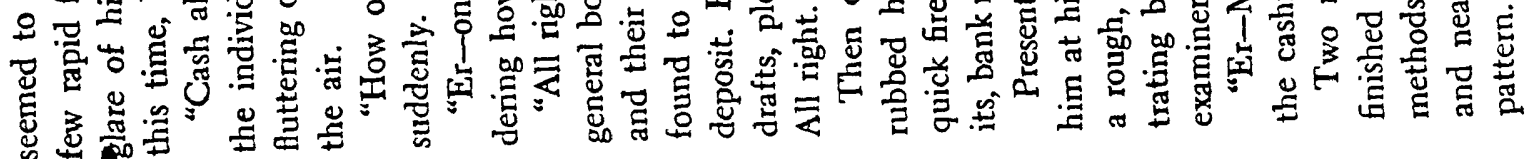

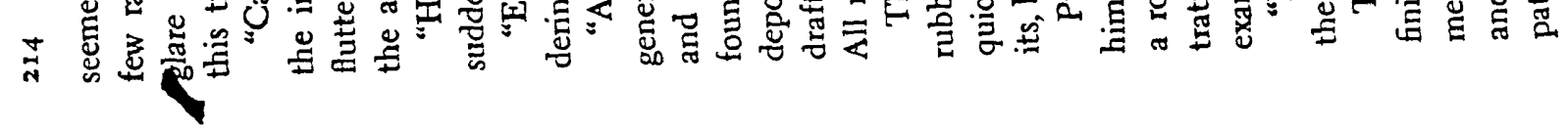




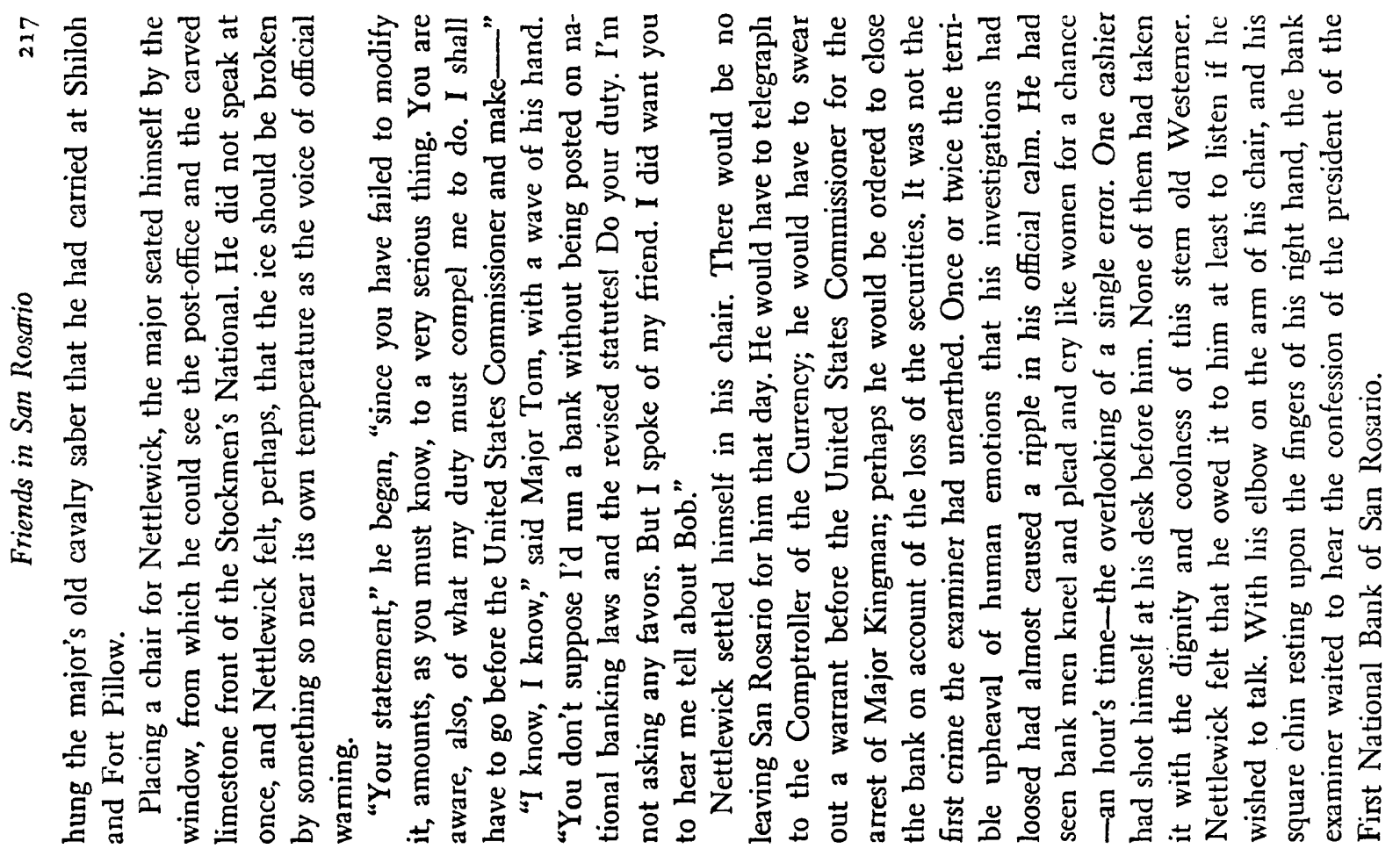

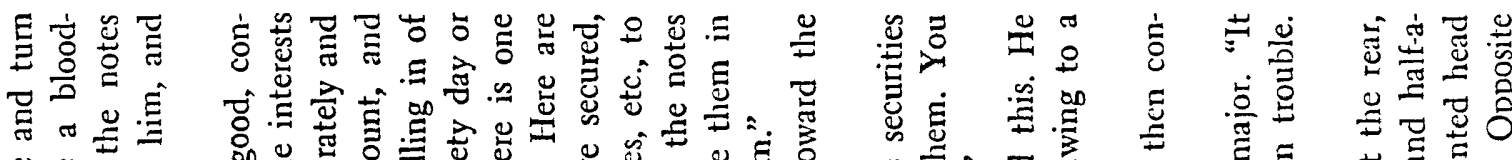

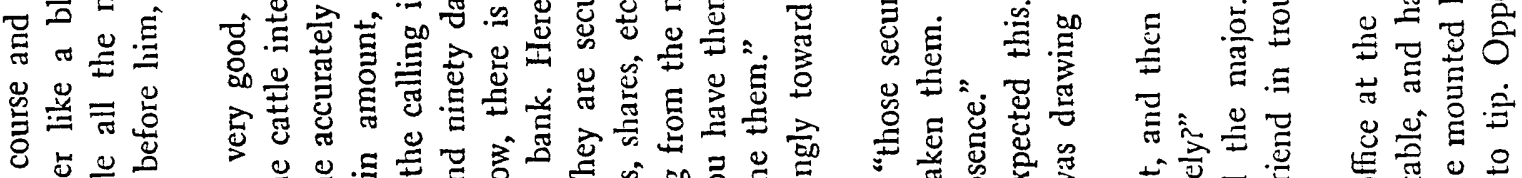

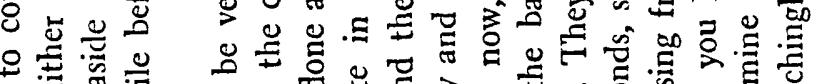

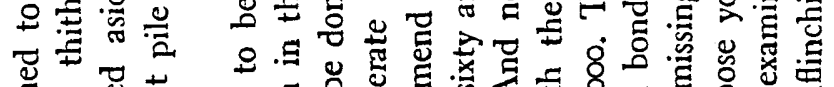

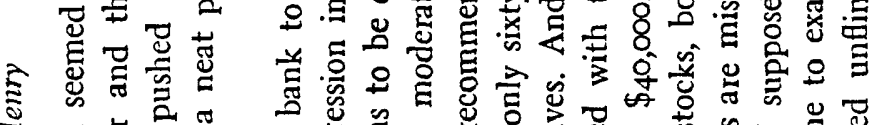

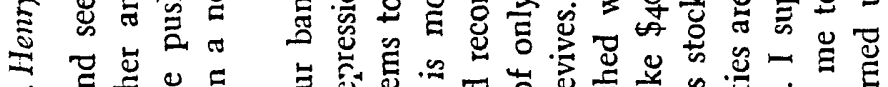

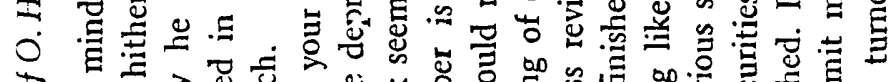

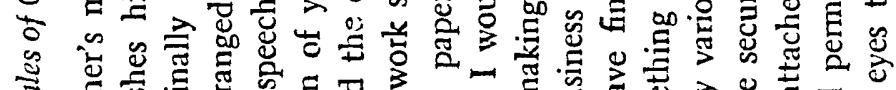

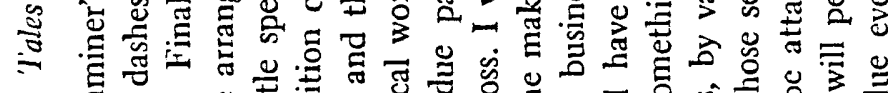

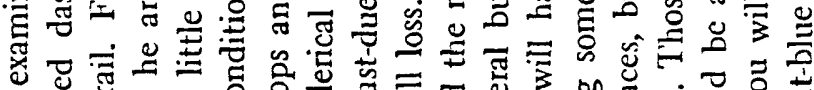

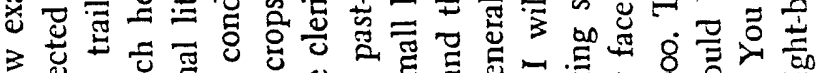

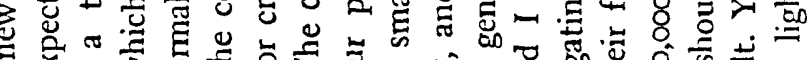

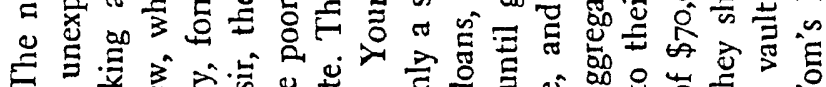

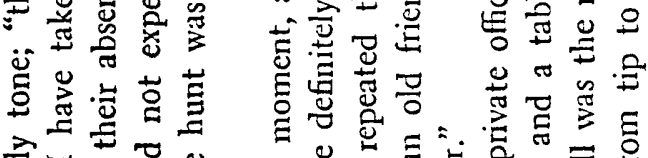

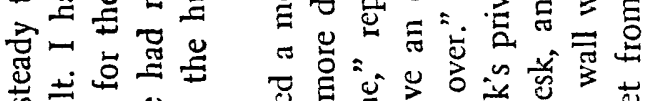

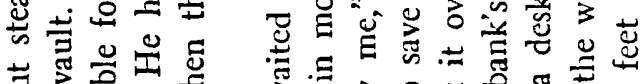

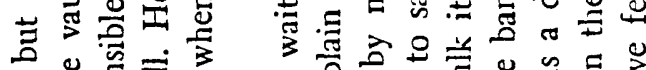

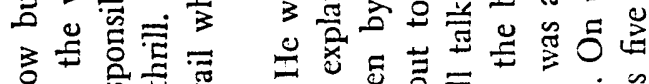

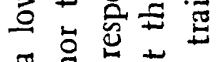

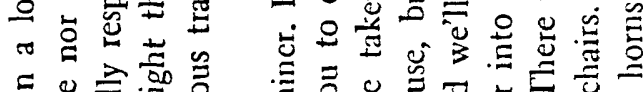

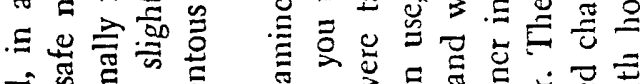

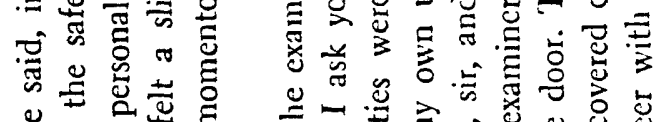

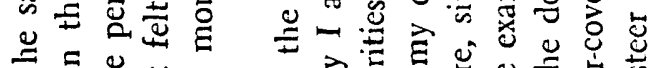

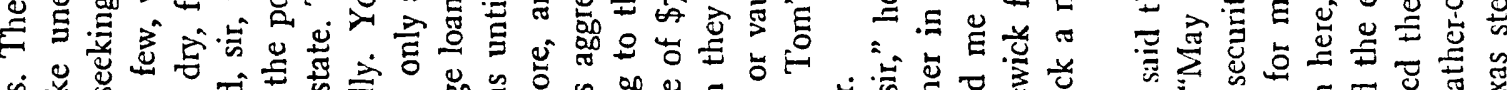

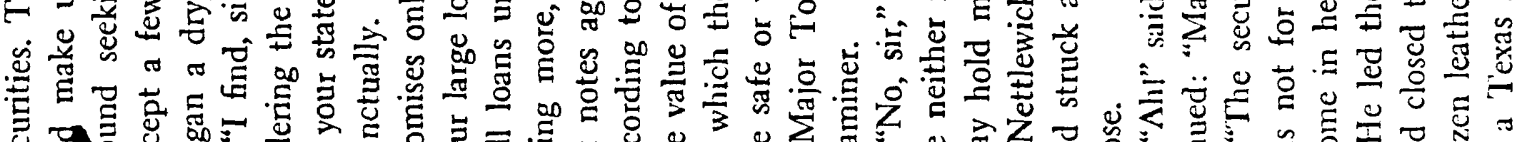

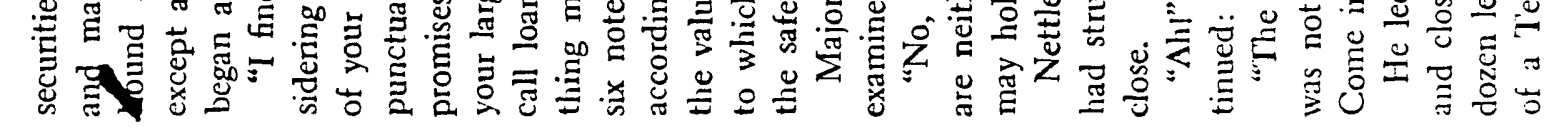




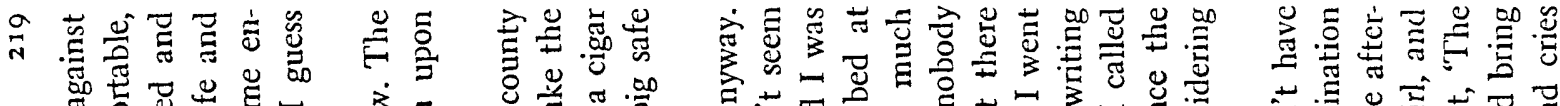

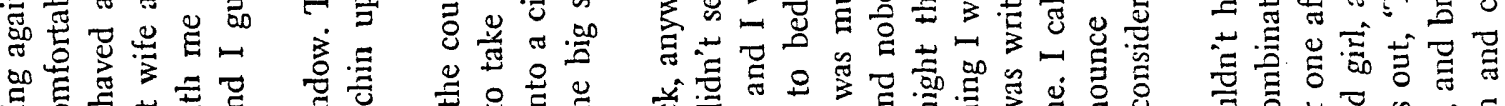

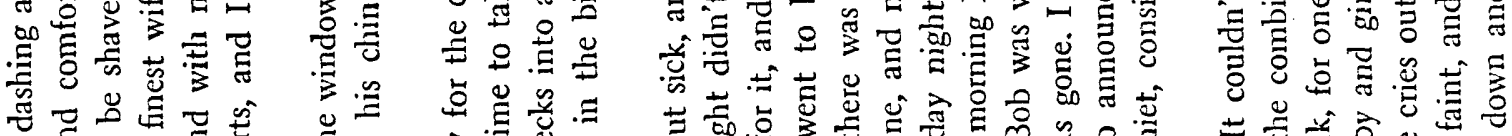

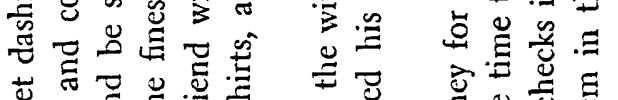

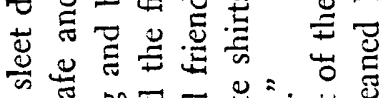

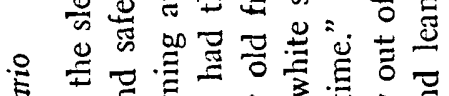

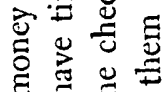

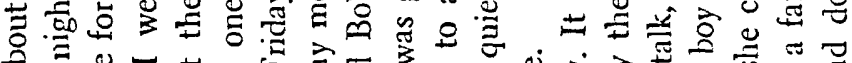

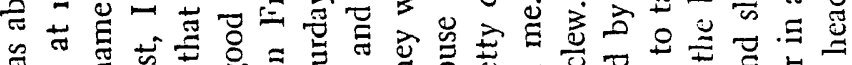

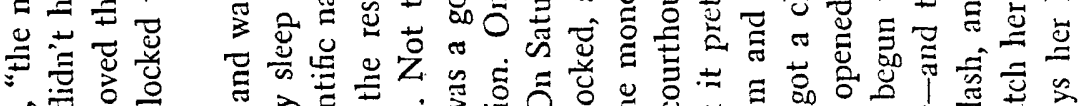

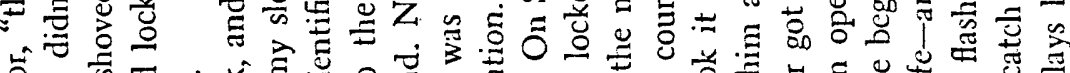

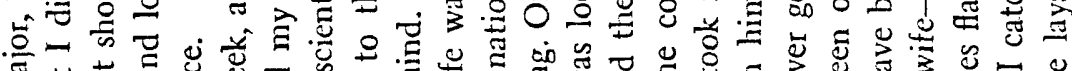

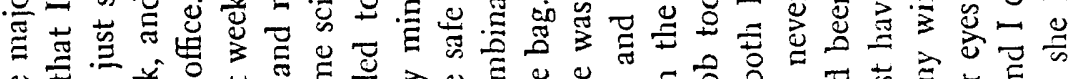

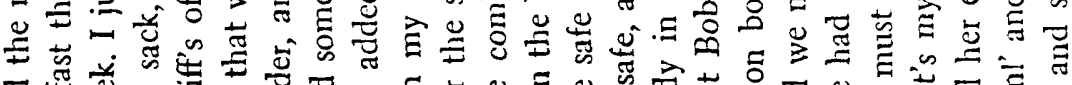

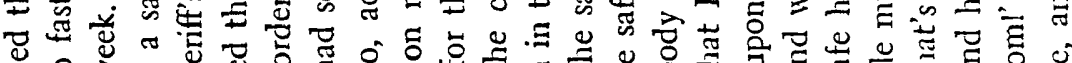

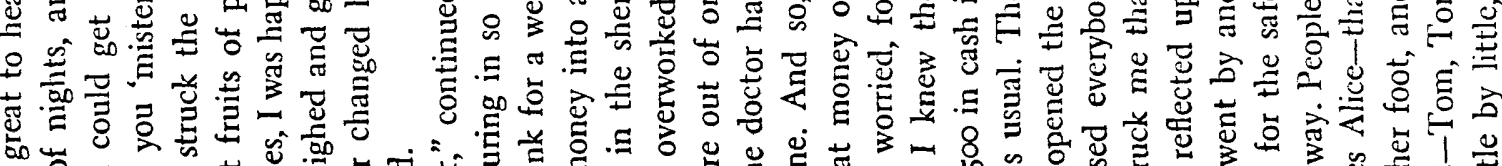

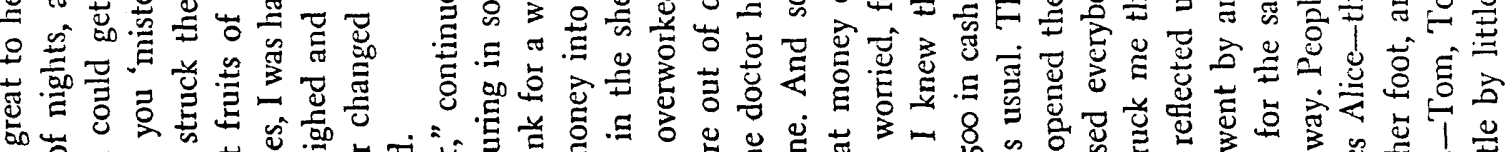

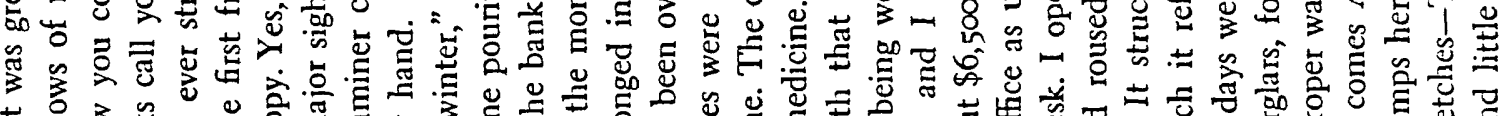

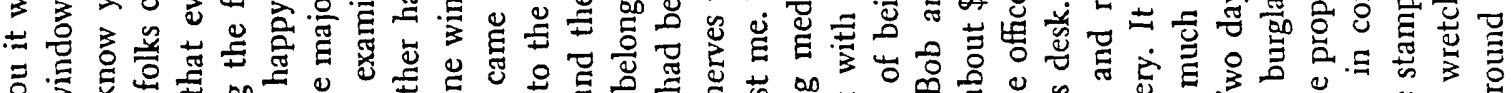

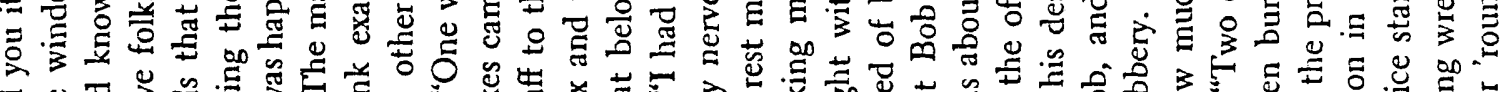

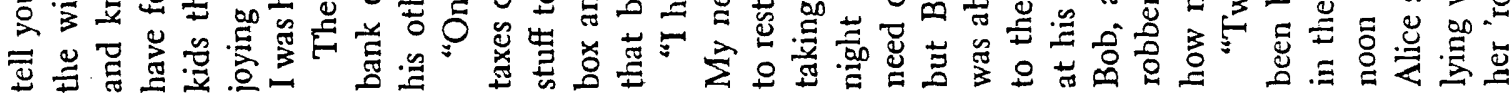

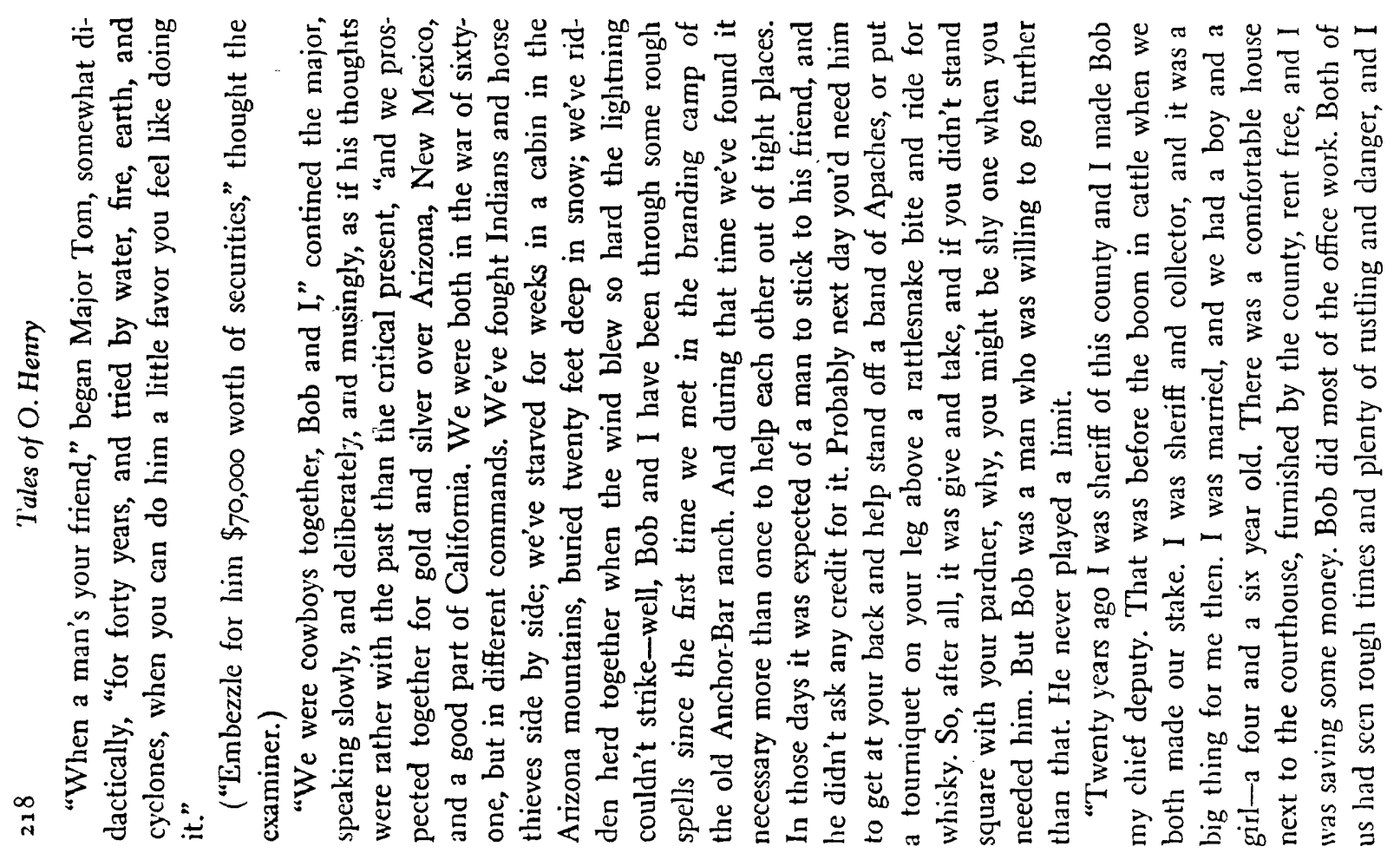




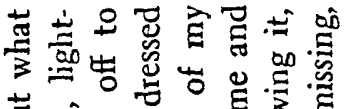

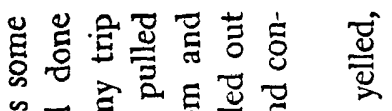

จ $\quad 0$

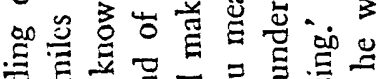

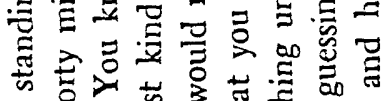

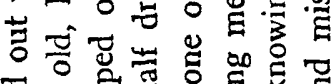

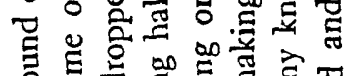

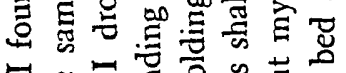

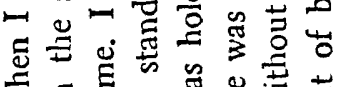

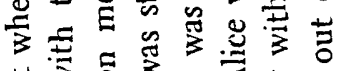

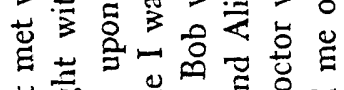

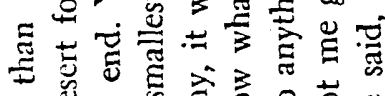

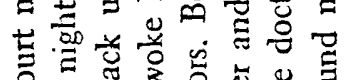

E $\approx \infty \mathrm{S}$

$. \Xi 5 . \Xi \Xi$

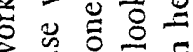

त $\overline{5}$

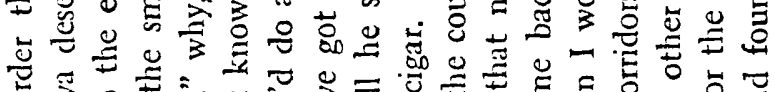

요욜

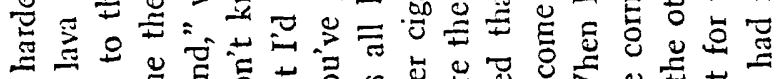

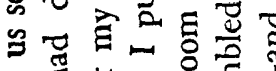

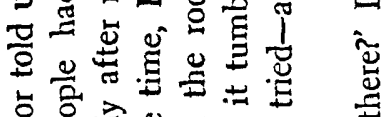

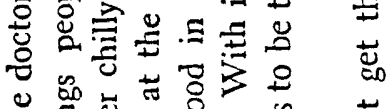

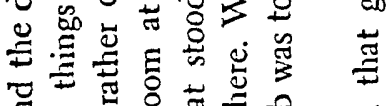

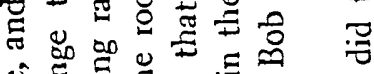

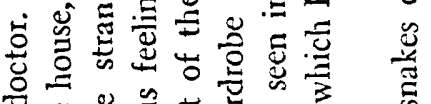

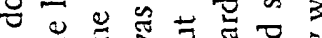

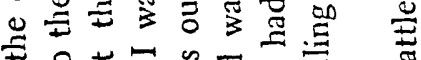

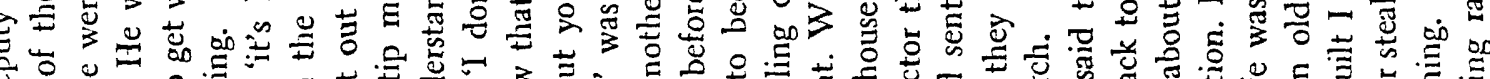

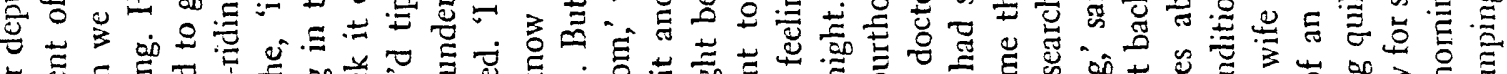

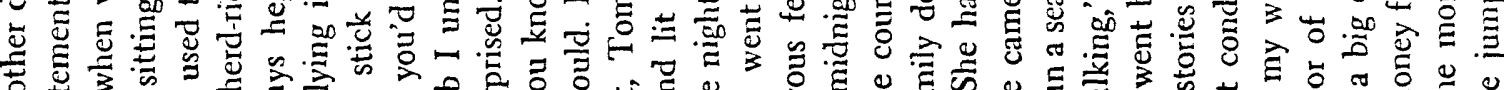

월

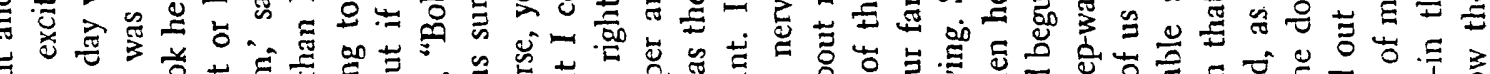

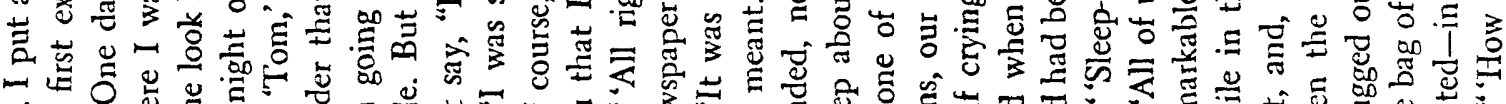

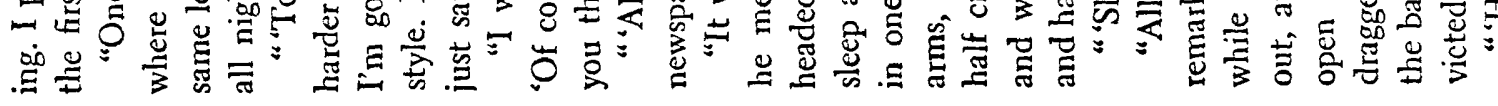

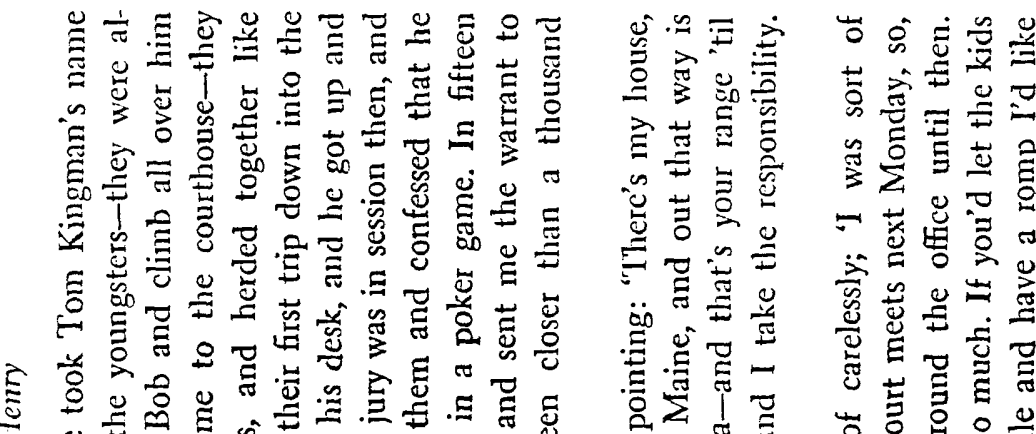

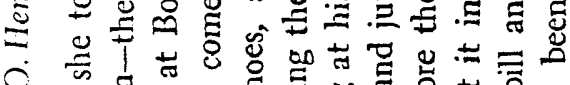

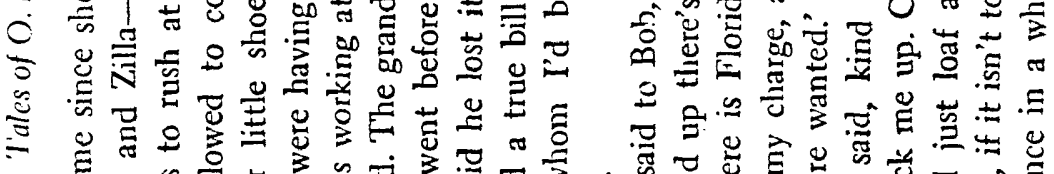

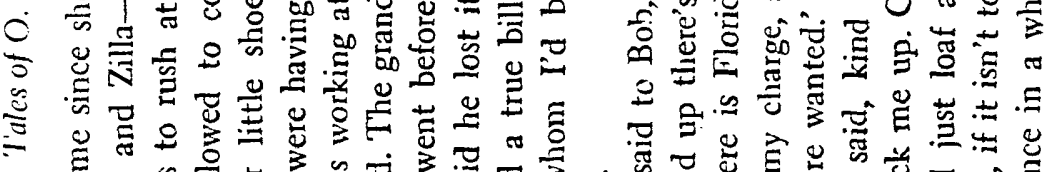

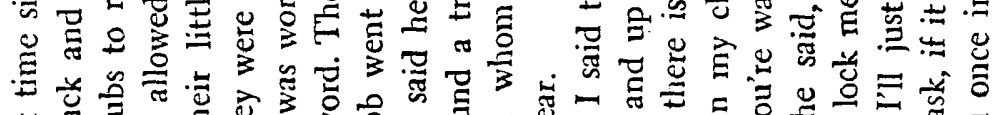

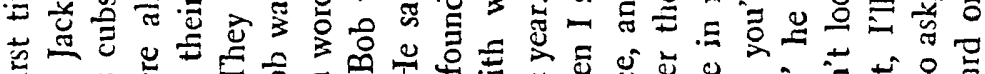

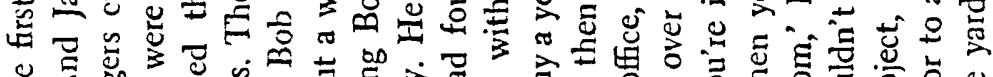

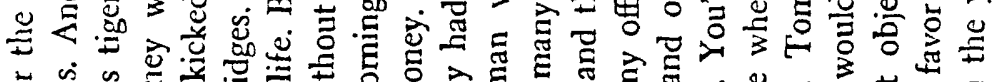

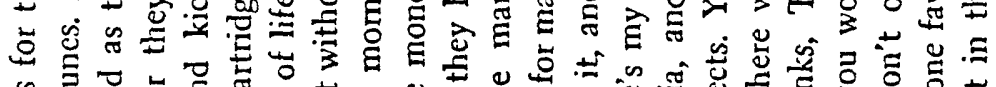

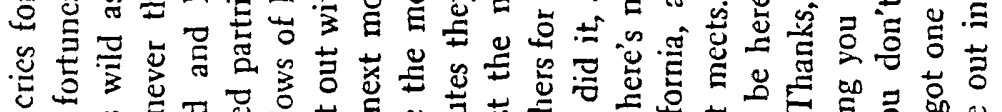

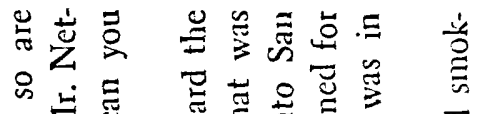

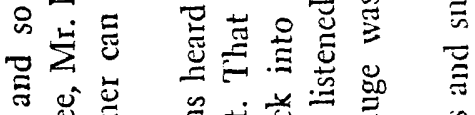

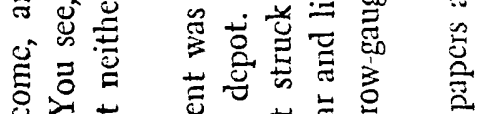

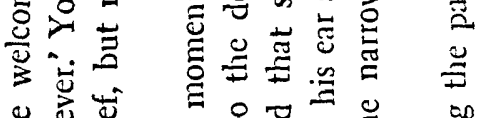

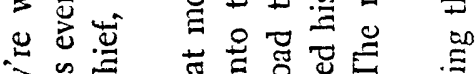

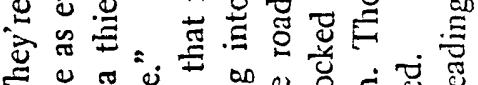

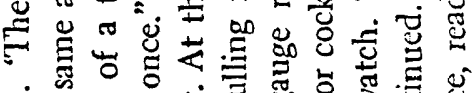

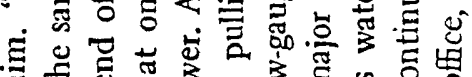

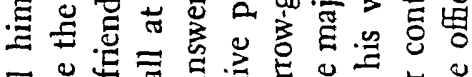

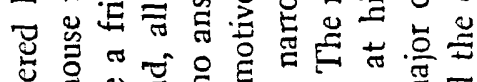

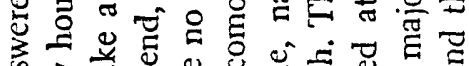

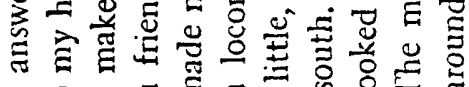
一ㄴㅇㅛ

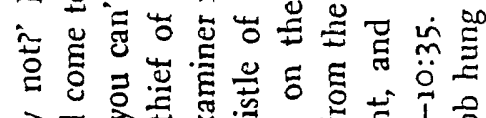

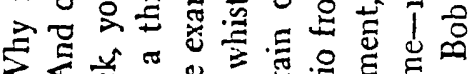

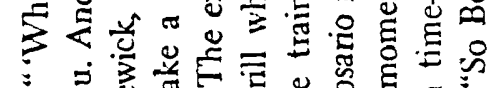




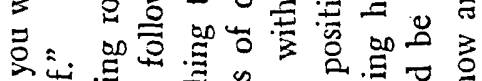

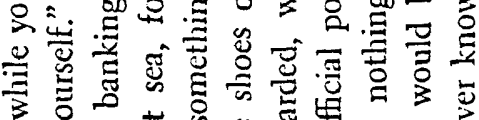

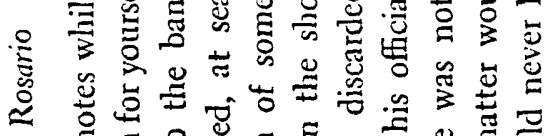

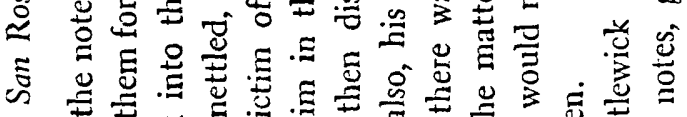

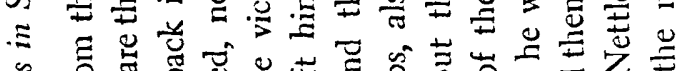

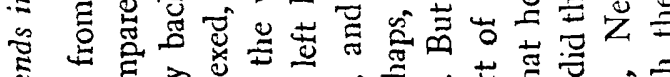

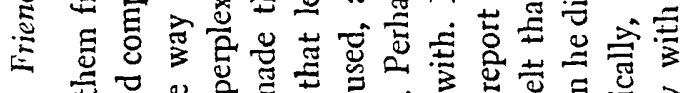

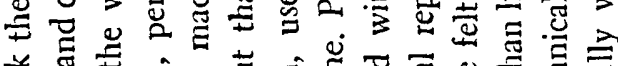

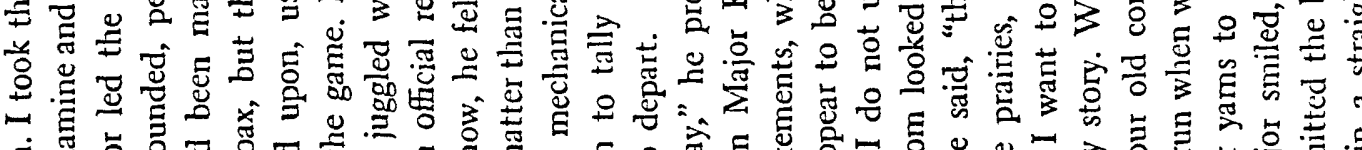

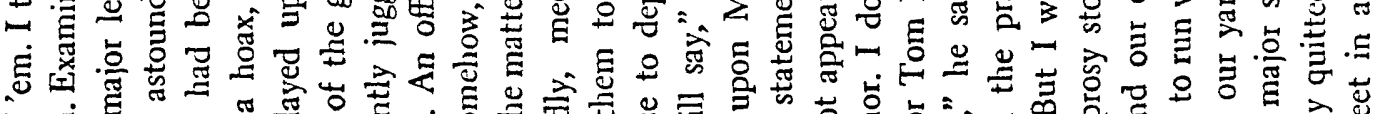

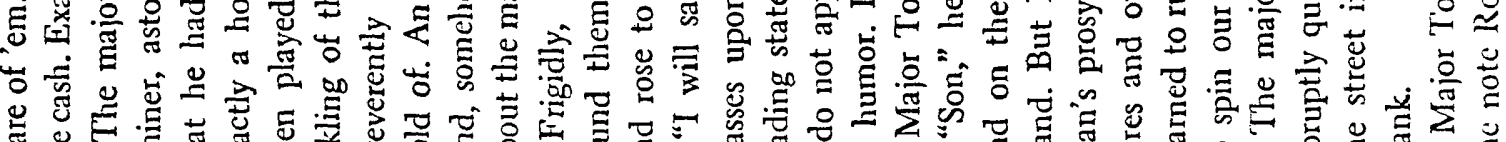

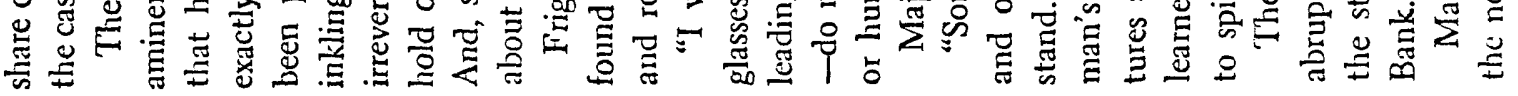

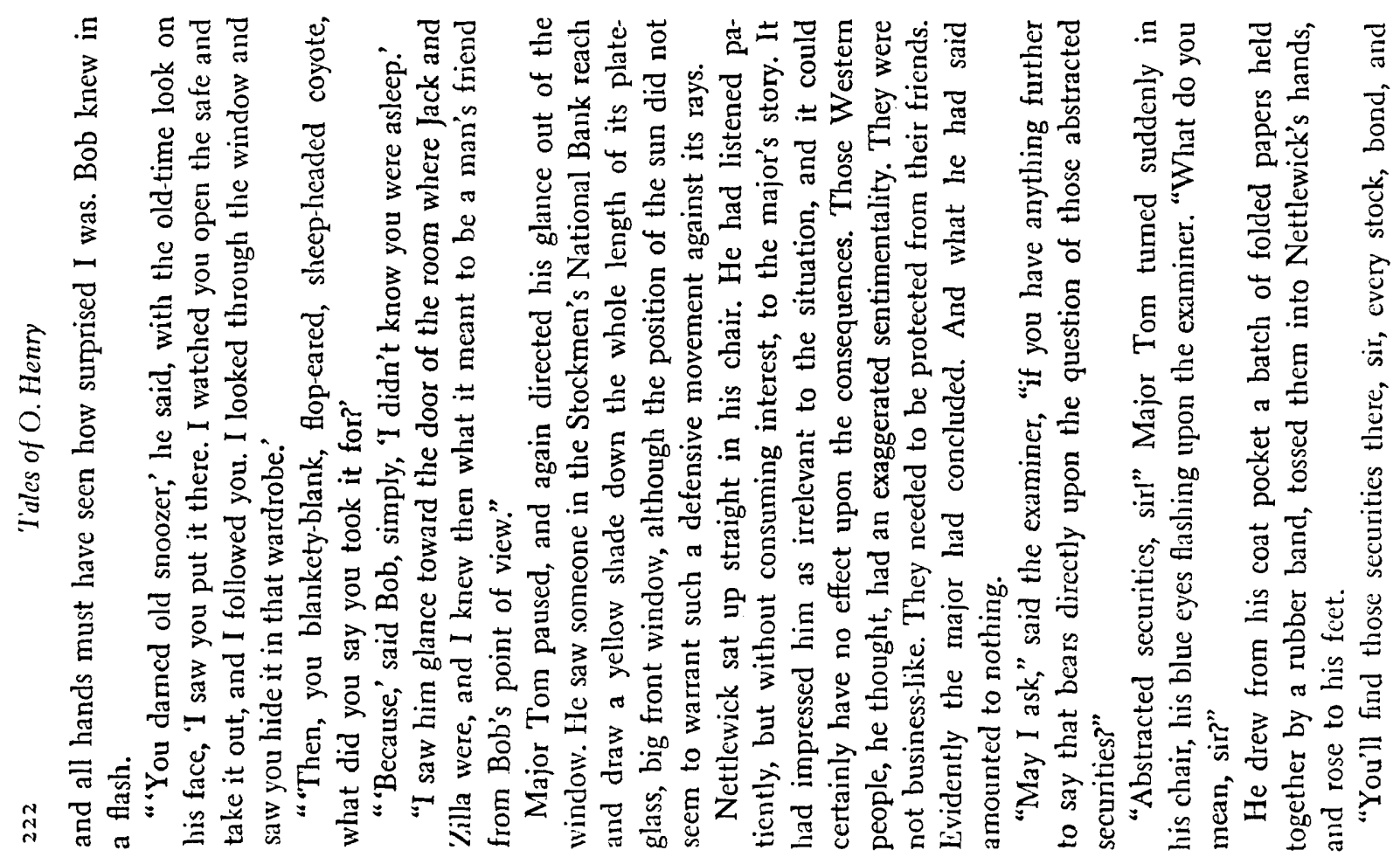




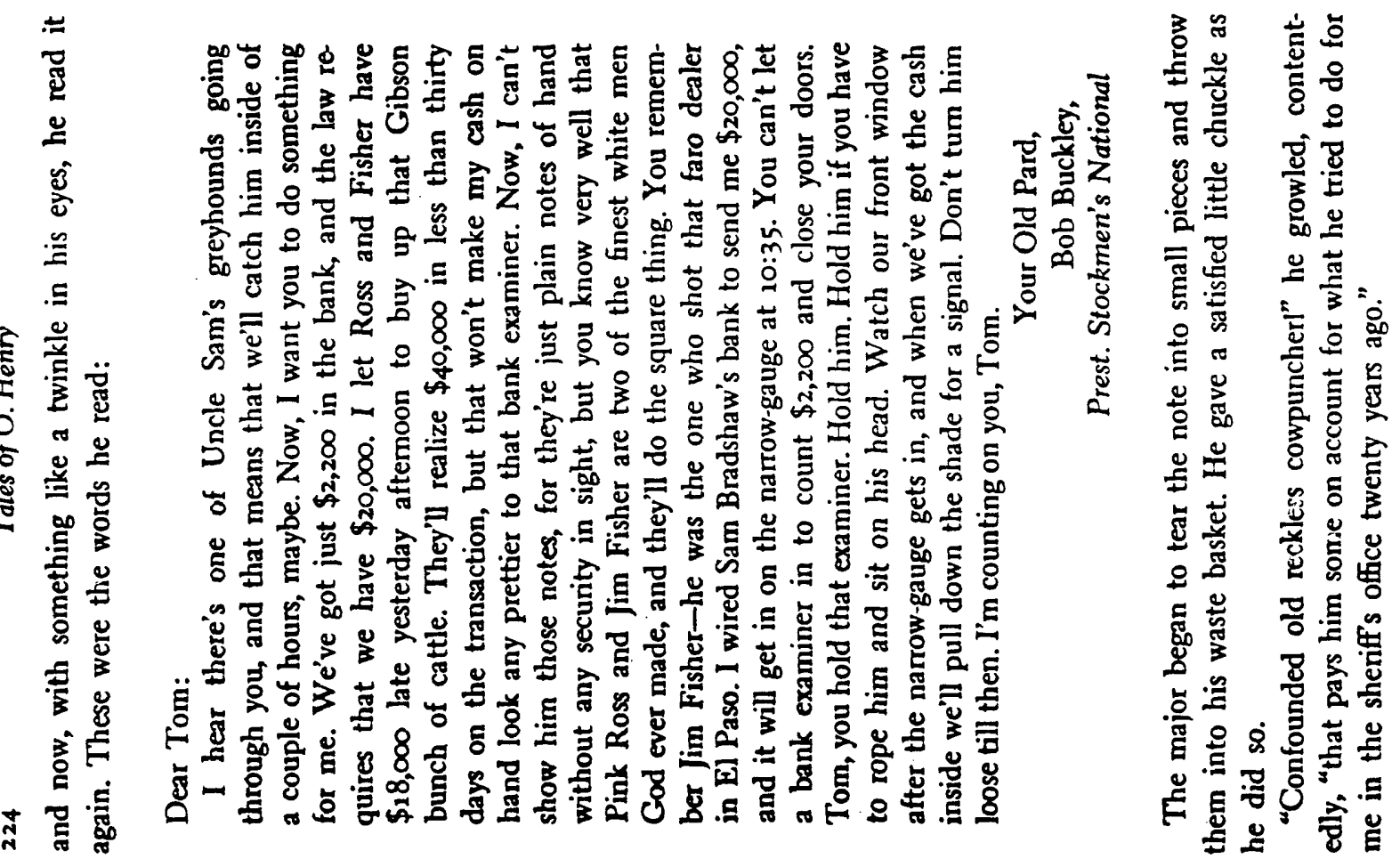


VITA

Holly B. Drewer

The author was born on September 26, 1964 in Belle Haven, Virginia. She received her Bachelor of Arts in English from James Madison University in May, 1986, and entered the Master of Arts program in psychology at the college of William and Mary in August, 1988. Her first year project, entitled "The Relationship between Self-Report Measures of Schizotypy and Cognitive Performance," was presented to the southwestern Psychological Association in April, 1990. 